\author{
David Wilson
}

\title{
Associação de haplótipos de genes do sistema serotonérgico e impulsividade
}

Dissertação apresentada à Faculdade de Medicina da Universidade de São Paulo para obtenção de título de Mestre em Ciências.

Área de concentração: Psiquiatria

Orientador: Prof. Dr. Homero Pinto Vallada Filho

São Paulo 
À minha amada esposa Esther, a meu amado filho Daniel, pelo conforto de seu amor e companhia inigualáveis.

A meus pais, Pelo exemplo de perseverança. 


\section{AGRADECIMENTOS}

Ao Prof. Dr. Homero Pinto Vallada Filho, pela orientação.

À Profa. Dra. Daniela Sabbatini da Silva Lobo, pela inestimável ajuda na forma de estímulo, sugestões e olhar crítico.

Ao Ambulatório de Jogo Patológico do Instituto de Psiquiatria da FMUSP, na pessoa do Prof. Dr. Hermano Tavares, pela oportunidade de trabalho. 


\section{SUMÁRIO}

Lista de Tabelas

Lista de Figuras

Resumo

Abstract

1. INTRODUÇÃ̃O

1.1 Comorbidades Psiquiátricas em Jogo Patológico

1.2 Investigações Neurobiológicas em Jogo Patológico 
$\begin{array}{lll}4.1 & \text { Casuística } & 21\end{array}$

4.1.1 Avaliação Clínica 21

4.1.2 Critérios de Inclusão e Exclusão 22

$\begin{array}{lll}4.2 & \text { Extração de DNA } & 23\end{array}$

4.3 Escolha de Polimorfismos para a Análise de Haplótipos 24

$\begin{array}{lll}4.4 & \text { Genotipagem } & 31\end{array}$

4.4.1 Gene do Transportador de Serotonina (SLC6A4) 31

4.4.2 Gene do Receptor de Serotonina Subtipo 1B (5HT1B) 32

4.4.3 Gene do Receptor de Serotonina Subtipo 2A (HTR2A) 33 
6.3 Investigação da Associação entre Jogo Patológico e Genes

Envolvidos na Atividade Serotonergica Cerebral 
Patológico

7. CONCLUSÕES

8. REFERÊNCIAS BIBLIOGRÁFICAS 


\section{LISTA DE TABELAS}

Tabela 1 - Dados sociodemográficos de JP comparados a irmão NJP

Tabela 2 - Comparação de comorbidades psiquiátricas JP e irmão NJP

Tabela 3 - Teste de associação alélica e genotípica para o polimorfismo 5HTTLPR em 140 pares de irmãos discordantes para o diagnóstico de JP, UNPHSED 3.0.10

Tabela 4 - Teste de associação alélica e genotípica para o polimorfismo HTR1BG681C em 140 pares de irmãos discordantes para o

Diagnostico de JP, UNPHASED 3.0.10

Tabela 5 - Teste de associação alélica e genotípica para o polimorfismo HTR2AT102C em 140 pares de irmãos discordantes para o Diagnóstico de JP, UNPHASED 3.0.10

Tabela 6 - Teste de associação alélica e genotípica para o polimorfismo HTR2AC516T em 140 pares de irmãos discordantes para o diagnóstico de JP, UNPHASED 3.0.10

Tabela 7 - Teste de associação de haplótipos, método "sliding windows", Para os polimorifmsos HTR2A (C516T) e (T102C) em 140 pares de 


\section{LISTA DE FIGURAS}

Figura 1: $\quad$ Single nucleotide polymorphisms (SNPs) no gene HTR2A, de acordo com os dados para população caucasiana do projeto HapMap

Figura 2: $\quad$ Single nucleotide polymorphisms (SNPs) no gene SLC6A4, de acordo com os dados para população caucasiana do projeto HapMap

Figura 3: $\quad$ Single nucleotide polymorphisms (SNPs) no gene HTR1B, de acordo com os dados para população caucasiana do projeto HapMap

Figura 4: $\quad$ Single nucleotide polymorphisms (SNPs) selecionados (tagged SNPs) no gene HTR2A de acordo com os dados para população caucasiana projeto HapMap

Figura 5: $\quad$ Single nucleotide polymorphisms (SNPs) no gene SLC6A4 selecionados (tagged SNPS) de acordo com os dados para população caucasiana do projeto HapMap

Figura 6 Single nucleotide polymorphisms (SNPs) no gene SLC6A4 selecionados (tagged SNPS) de acordo com os dados para 


\section{RESUMO}

Dadas a elevada prevalência e os grandes prejuízos sociais, familiares e pessoais que caracterizam o envolvimento patológico com jogos de azar, torna-se necessária a investigação sistemática de fatores de vulnerabilidade e de resistência que possam influir no desenvolvimento de tais condições. Uma das principais estratégias utilizadas para a profilaxia e tratamento dessas formas de envolvimento patológico tem sido a investigação dos componentes biológico-genéticos do Jogo Patológico (JP). O presente estudo objetivou investigar a associação de polimorfismos de genes candidatos do sistema serotonérgico e JP em pares de irmãos discordantes para este diagnóstico. Participaram do estudo 140 pares de irmãos discordantes para o diagnóstico de JP pelos critérios do Manual Diagnóstico e Estatístico da Associação Psiquiátrica Americana, DSM-IV. Foram genotipados os seguintes polimorfismos de genes que codificam: o transportador da serotonina (polimorfismo 5HTTLPR-1/s), o receptor serotoninérgico subtipo 1B (5HT1B G861C), e o receptor serotoninérgico subtipo 2A (polimorfismos 5HT2A T102C e C516T). Na análise estatística observou-se uma maior distribuição do alelo $\mathrm{C}$ do polimorfismo T102C do gene 5HT2A no grupo de irmãos com o diagnóstico de JP $(\mathrm{p}<0,01)$, sugerindo uma possível contribuição desse alelo na predisposição ao JP. Entretanto, faz-se necessária a investigação desses polimorfismos em amostras independentes envolvendo o fenótipo JP para a confirmação dos achados apresentados nesse trabalho. Uma análise preliminar dos haplótipos (102 e 516) apresentou resultados inconclusivos. É interessante notar que há associação entre esse polimorfismo e manifestações psiquiátricas outras que não o JP. 


\begin{abstract}
The high prevalence and the great social, familial and personal hazards that appear along with the occurrence of pathological involvement in gambling makes it necessary to systematically investigate vulnerability and resilience factors that may influence the development of such a condition. One of the main strategies in prevention and treatment of these pathological behaviors has been the investigation of the biological-genetic basis of pathological gambling (PG). The present study aimed to determine any association between candidate gene polymorphisms of the serotoninergic system and the occurrence of PG in sib-pairs discordant for this diagnosis. One hundred and forty (140) PG-discordant sib-pairs were evaluated by the Diagnostic and Statistical Manual from the American Psychiatric Association (DSM-IV), who had already been previously genotyped in other studies. We genotyped the polymorphisms which codified: the serotonin transporter (5HTTLPR1/s polymorphism), the serotonergic receptor subtype 1B (5HT1B G861C polymorphism), and the serotonergic receptor subtype 2A (T102C and C516T polymorphisms). Statistical analysis revealed a greater distribution of the $\mathrm{C}$ allele of the T102C polymorphism of the 5HT2A gene in the gambling sib group $(\mathrm{p}<0,01)$, suggesting a possible contribution of this allele in the predisposition for PG. Nevertheless, it is necessary to further investigate these polymorphisms in independent samples involving PG phenotype for the adequate confirmation of such findings. A preliminary analysis of the haplotypes (102 and 516) show inconclusive results. It is noteworthy that there are previous associations between this polymorphism and psychiatric manifestations other than PG.
\end{abstract}





\section{INTRODUÇÃO:}

O envolvimento excessivo com apostas, reconhecido desde a Antiguidade, passou a ser considerado como transtorno psiquiátrico a partir de sua inclusão no Manual Diagnóstico e Estatístico dos Distúrbios Mentais em 1980 (DSM-III-R APA 1980), sob a denominação de Jogo Patológico (JP). Embora não se tenha dados disponíveis no Brasil até o momento, estima-se que seja um transtorno bastante freqüente. Com prevalências variando entre 0,8 e $4 \%$ da população geral em estudos realizados nos EUA, Canadá e Austrália (Shaffer et al., 1999, Shaffer e Korn, 2002, Schofield et al., 2004), fica evidente a importância desse diagnóstico. Ladoucer demonstrou que aproximadamente $88 \%$ da população canadense teve ao menos um contato com jogos de azar ao longo da vida (Ladoucer et al., 1991). Em meta-análise do comportamento de apostas nos EUA e Canadá, Shaffer estimou que $86 \%$ da população desses dois países podem ser considerados como apostadores recreativos (Shaffer et al., 1997), evidenciando assim a disseminação do hábito de apostar.

Além da prevalência, também a gravidade social do JP tem interesse, em particular no impacto que o hábito de jogar tem nas famílias e em filhos de jogadores, e os riscos, ainda não conhecidos, de consequiências comportamentais tardias em conseqüência da exposição ao esfacelamento financeiro e pessoal do JP (Darbyshire et al., 2001), inclusive o desemprego (Beaudoin e Cox, 1999). Esses dados ressaltam a importância dos problemas com jogos de azar, devido à gravidade das conseqüências 
sociais dos mesmos, tais como a pulverização dos recursos pessoais e familiares, o desgaste dos relacionamentos e a perda de crédito que decorrem diretamente das feições clínicas deste problema (APA, 1996).

O gosto por atividades e estilos de vida em que o risco tem grande importância é um traço freqüente nos jogadores patológicos, traço este associado à busca por sensações, e características impulsivas de personalidade, conforme Zuckerman (1994) e Blaszczynski et al. (1997). A busca pela sensação imediata de gratificação é também uma característica comum em indivíduos impulsivos (Chambers et al., 2003), sendo, portanto, verificada nos casos de dependência química ou comportamental, como é o caso do JP (Ibañez et al., 2001).

A impulsividade tem sido mais freqüentemente definida como "qualquer comportamento que visasse um objetivo específico, caracterizado por um julgamento precário na obtenção de gratificação, tal como drogas de adição, sexo, comida, entre outros" (Chambers et al., 2003).

Evenden, no entanto, questiona a validade da atual conceituação de impulsividade, e alerta para o fato de a impulsividade que é descrita em diferentes transtornos poder ter características distintas, fato que levou a alguns conceitos conflitantes de impulsividade, com uma tendência a enfocar a natureza da manifestação comportamental, tal como "problemas com a lei", "agressão", "uso de drogas", “dificuldades escolares”, e não os processos psicológicos comuns aos transtornos. Em população normal, foram aplicados questionários de personalidade, e os resultados 
sugerem que diferentes questionários abordam diferentes aspectos da impulsividade, e que esses aspectos podem ter bases biológicas distintas (Evenden et al., 1999).

Mais recentemente, estudos comparando características de personalidade de jogadores patológicos com portadores de transtorno obsessivo-compulsivo concluíram que os jogadores eram menos compulsivos e tinham traços impulsivos mais proeminentes (Tavares, 2001; Kim e Grant, 2002). Dadas as características do JP, de um comportamento disadaptado, envolvendo perda de controle nas apostas, deterioração progressiva do transtorno, e persistência no comportamento apesar de consequências negativas, a "ocorrência de um comportamento impulsivo repetitivo" (Lejoyeux et al., 2000), este é hoje considerado uma dependência comportamental (NORC 1999, Ibañez et al., 2001).

Seth comenta a participação ambiental necessária para o desencadeamento e manutenção do comportamento de JP, ao levantar o dado de que em estados norteamericanos em que há maiores oportunidades de apostar, também ocorre maior prevalência de JP, também apontando, no mesmo trabalho, para a vulnerabilidade familiar como um fator decisivo na ocorrência de JP (Seth et al.,1998). Esses dados demonstram o caráter importante da familialidade na participação no JP.

\subsection{COMORBIDADES PSIQUIÁTRICAS EM JOGO PATOLÓGICO:}

Em diversos transtornos psiquiátricos, tem-se tornado cada vez mais evidente a ocorrência de manifestações psicopatológicas menores e sintomas de intensidade 
subclínica, que permitem a formulação de um segundo diagnóstico, paralelo, com implicações diagnósticas e terapêuticas próprias (Shankman et al., 2007). Essa evidência tem motivado um número grande de estudos que visam detalhar as características psicopatológicas e comórbidas do JP.

Kotler encontrou índices elevados de co-morbidade entre Jogo Patológico e outras condições psiquiátricas: abuso de álcool e drogas, depressão e ansiedade (Kotler et al., 2006).

Mais especificamente, a co-morbidade entre JP e dependência ou abuso de drogas tem sido evidenciado por grande numero de estudos de diferentes desenhos, todos demonstrando robusta associação entre ambas (Castellani et al., 1996; Ibañez et al., 2001; Lesieur et al., 1986; Petry, 2000; Stewart et al., 2003).

A partir do Estudo Epidemiológico Nacional em Álcool e Condições Associadas (National Epidemiologic Survey on Alcohol and Related Conditions - NESARC), Petry encontrou uma prevalência ao longo da vida de $0,42 \%$, para JP, que se associou com diversos transtornos psiquiátricos: $73,2 \%$ com abuso de alcool, $60,8 \%$ com transtorno de personalidade, $60,4 \%$ com nicotina, $49,6 \%$ com transtorno do humor, $41,3 \%$ com ansiedade e 38,1\% com drogas (Petry et al., 2005). Essa associação consistente entre JP e dependências químicas sugere sua inclusão dentro das dependências comportamentais.

A elevada comorbidade entre ADHD e Jogo Patológico (Dell'Osso et al., 2005; Hollander et al., 2005) sugere que ambas condições partilhem mecanismos neurofuncionais semelhantes. Dentro da organização nosográfica do DSM-IV, o JP está incluído juntamente com outros transtornos do impulso (Piromania, Tricotilomania, 
Compras Compulsivo-Impulsivas), alguns até descritos posteriormente ao JP (p.ex.,Transtorno Compulsivo-Impulsivo de Internet, Comportamento Sexual Excessivo), devido a evidências psicopatológicas, epidemiológicas e farmacológicas(Dell'Osso et al.,2006, Hollander et al.,2005; Toneatto et al., 2004; Potenza et al., 2002; Pallanti et al., 2002; Kim et al., 2002; Riboldi et al., 2002).

Segundo Mann, a função serotonérgica está implicada na etiologia e patogênese de diversas condições psiquiátricas maiores, como é exemplo angular o rebaixamento da função serotonérgica no comportamento suicida, tornando-a candidata a ter parte na diátese genética de um comportamento suicida que, segundo o autor, atravessaria diversas categorias diagnósticas (Mann et al., 2003).

Lesch constata que camundongos knock-out para genes do sistema serotonérgico apresentam índices elevados de agressividade e impulsividade em relação a camundongos selvagens, e propõe a investigação sistemática das vias serotonérgicas no estudo da impulsividade humana (Lesch et al., 2000).

\subsection{INVESTIGAÇÕES NEUROBIOLÓGICAS EM JOGO PATOLÓGICO:}

Com o desenvolvimento das diversas áreas das neurociências, tem havido um grande aumento nas investigações biológicas e cerebrais em modelos animais, bem como investigações aplicadas aos transtornos do comportamento, desde os mais antigos, como a esquizofrenia os transtornos afetivos, quanto os de conceituação e diagnóstico mais recente, como é o caso do JP. 
Olds e Milner (1954), em seu trabalho pioneiro, identificaram as áreas cerebrais responsáveis pelo reforço comportamental positivo. Através da colocação de eletrodos de estimulação em determinadas áreas do cérebro de ratos, os mesmos registraram o desencadeamento de um comportamento de auto-estimulação ativa e intensa, que tendia a se intensificar com o tempo, acabando por adquirir feições imperiosas, em sacrifício de outras atividades, inclusive as mais fundamentais e necessárias à sobrevivência, como a alimentação (Olds e Milner, 1954). Esse conjunto de áreas que desencadeou tal comportamento de auto-estimulação foi denominado Sistema Cerebral de Recompensa, sendo anatomicamente delimitado pela região que vai desde a área tegmentar ventral até o núcleo acumbens, tubérculo olfatório, núcleo estriado e córtex frontal (Olds e Milner, 1954; Wise e Rompre, 1989; Koob et al., 1992; Koob et al., 2001). Esse sistema sofre ação regulatória de sistemas inibitórios, em que a serotonina exerce papel capital (Kalivas et al., 1993; Nielsen et al., 1994).

Segundo Monterosso (2004), os estudos de impulsividade em animais têm focado principalmente em paradigmas que têm em comum a medida da impulsividade como uma função diretamente proporcional à velocidade de perda de valor com o tempo (Função do Desconto Temporal), mas que estes apresentam limitações em suas aplicações à condição humana, onde a díade impulsividade/auto-controle teria papel central (Monterosso et al., 2004).

Fiorillo propõe que o padrão de ativação dopaminérgica frente à participação em atividades de resultado imprevisível apresentaria particularidades de ativação e sustentação que favoreceriam tanto o aprendizado quanto a habituação aditiva, e sugere 
esse padrão como um dos fatores neurobiológicos que contribuiriam para o perfil aditivo do JP, dado o caráter imprevisível dos resultados dos jogos de azar (Fiorillo et al., 2003).

Diversos estudos têm implicado o córtex prefrontal como uma estrutura diretamente envolvida nas manifestações de impulsividade, especialmente em sua atividade inibitória da execução de atos, em grande parte regulada pela serotonina (Chambers et al., 2003; Fiorillo et al., 2003).

Em estudo submetendo voluntários normais à depleção aguda de triptofano evidenciou-se diminuição da concentração de serotonina no SNC, que por sua vez se associou a um aumento de respostas de estilo impulsivo e desinibido, bem como a uma diminuição da capacidade discriminatória na execução de tarefas verbais (Walderhaug $e t$ al., 2002).

Em estudo de Ressonância Magnética Funcional (fMRI) demonstrou-se que indivíduos agudamente depletados de triptofano, executando tarefas de resposta motora de "sim"-“go" ou "não"-“no go") apresentavam diminuição de ativação da porção órbito-inferior direita do córtex prefrontal bem como uma ativação em córtex temporal superior e medial, fornecendo evidências sobre o papel destas regiões, cuja inervação é principalmente serotonérgica, em atividades de controle motor inibitório (Rubia et al., 2005).

Semelhantemente, Puig implica uma disfunção do córtex prefrontal na etiologia de condições psiquiátricas em que a impulsividade tem expressão central, como depressão maior e esquizofrenia (Puig et al., 2005), e investigações acerca de interações corticoestriatais apontam para a existência de um mecanismo de disfunção prefrontal também 
nas dependências, tanto químicas (Koob et al., 2001), quanto nas comportamentais, como é o caso do JP (Cavedini et al., 2002). Ainda, Koob e LeMoal hipotetizam que haveria um desbalanço entre sistemas promotores de gratificação e sistemas que teriam ação de "anti-recompensa" no desencadeamento e manutenção de comportamentos aditivos, onde, além de estimular as estruturas de gratificação, o uso de psicotrópicos também teria a função de inibir essas segundas estruturas (Koob e LeMoal, 2008), e cada vez mais tem-se extendido o conceito de adição aos comportamentos excessivos que não apresentam, em sua clínica, uso patológico de substâncias psicoativas, como é o caso do Jogo Patológico (Masaki et al., 2007).

Segundo Riboldi, esse funcionamento anormal do córtex orbitofrontal tanto em JP quanto em outros transtornos (p.ex., transtorno obsessivo-compulsivo e dependências químicas) pode ser entendido como um substrato neurofuncional comum para impulsividade, que atravessaria diversas categorias diagnósticas (Riboldi et al., 2002). Além disso, Potenza argumenta que uma alteração da função do córtex prefrontal, independentemente de qualquer diagnóstico específico, poderia por si só aumentar a probabilidade de ocorrência de impulsividade (Potenza et al., 2003; Stanley et al., 2000; Roy et al., 1988), e Chambers, ainda, propõe que a impulsividade seria o resultado de qualquer desequilíbrio importante no funcionamento das estruturas promotoras e inibitórias da motivação na neurocircuitaria da gratificação (Chambers et al., 2003).

Lesch formula a impulsividade como sendo nuclear em comportamentos disadaptados, tais como agressividade, adição e suicídio, e aponta para a variabilidade na 
expressão de genes do sistema serotonérgico como responsável pela ocorrência de traços complexos de personalidade, como é o comportamento agressivo (Lesch et al., 2000).

Kalechstein comparou JP que nunca haviam sido submetidos a tratamento medicamentoso, com dependentes químicos a metanfetamina, e com controles normais, tendo identificado um bloqueio neurocognitivo em lobo frontal nos JP, que em algumas medidas neuropsicológicas chega a ser mais importante do que aquele registrado nos dependedentes de metanfetamina, ou seja, foi detectado um disfuncionamento neurocognitivo não-atribuível a substância exógena. Ressalta ainda que a etiologia desses déficits ainda não está estabelecida, e que esses dados sugerem que o JP poderia, por um lado, ser um estímulo ambiental para essa disfunção de lobo frontal, mas que, alternativamente, essa ausência exógena também pode estar indicando um forte componente constitucional subjacente e anterior a todo o desenvolvimento clínico do JP. (Kalechstein et al., 2007).

\subsubsection{ESTUDOS GENÉTICO-EPIDEMIOLÓGICOS EM JOGO PATOLÓGICO:}

Os estudos genético-epidemiológicos são geralmente a primeira abordagem na investigação de um possível componente genético de uma afecção.

Estudando-se amostras clínicas de JP, foram constatadas incidências que variaram entre $9 \%$ e $20 \%$ de Jogo Patológico entre parentes de $1^{\circ}$. Grau de jogadores patológicos diagnosticados (Ibañez et al.; Black et al., 2003), mostrando incidências de 7 a 16 vezes a da população geral (Phillipe e Vallerand, 2007). 
Tanto a agregação familiar quanto as co-morbidades em JP foram consistentemente confirmadas por estudos de Black et al. (2003, 2006) e Dannon et al. (2006), ao avaliar parentes de $1^{\circ}$. Grau de JP, e constatar prevalências estatisticamente significantes de alcoolismo, abuso de substâncias, JP, depressão e ansiedade.

Em estudo que utilizou a South Oaks Gambling Scale (SOGS), Gambino demonstrou um risco 6 vezes maior de ocorrência de JP em dependentes de substâncias do que na população geral. Nesse mesmo estudo, mostrou uma associação entre JP e ocorrência de "possível jogo problemático" (possible gambling problem - preenchimento insuficiente de critérios para JP) em geração parental até os avós, estimando que o risco devido a jogo-problema num dos avós eleva o risco de ocorrência de jogo-problema em 12 a 30 vezes a da população geral (Gambino et al., 2003).

Oei avaliou 198 famílias (com um total de 546 indivíduos participantes) captadas a partir de participação voluntária de estudantes primeiranistas de psicologia, via SOGS e a "Escala de Cognição Relacionada a Apostas" (Gambling Related Cognition Scale GRCS), tendo encontrado padrão de influência da cognição parental no comportamento de jogo detectado nos filhos, sendo indireta e via cognição da descendência também. Os resultados fazem olhar na direção de um possível mecanismo de transmissão do comportamento, via cognição, de geração para geração (Oei et al., 2004).

A limitação desses estudos familiares é o fato de não permitirem uma boa discriminação entre o que pode ser genético e o que pode ser a influência ambiental no JP, discriminação essa que estudos entre gêmeos monozigóticos e dizigóticos conseguem detalhar. 


\subsubsection{ESTUDOS EM GÊMEOS:}

O pressuposto básico que rege os estudos em gêmeos seria de que, em condições onde a influência ambiental é intensa, gêmeos dizigóticos e monozigóticos teriam concordância diagnóstica próxima, enquanto que em condições predominantemente genéticas, essa concordância seria significativamente maior nos monozigóticos (partilhando estes praticamente 100\% dos loci) do que nos dizigóticos (os quais partilhariam em torno de $50 \%$ desses loci).

Eisen et al (1998) realizou amplo estudo com 3359 pares de gemelares, obtidos pelo "Registro dos gêmeos da Era do Vietnam" (Vietnam Era Twin Registry - VET), nos quais investigou, via entrevista telefônica, a presença de diferentes sintomas de JP (p.ex: tentar recuperar perdas no mesmo lugar da aposta, apostar quantias maiores do que o inicialmente desejado, etc), e sua respectiva freqüência em ambos membros fraternos. Usando o corte de um mínimo de 25 apostas/ano, constatou JP em apenas 1,4\% da amostra total (94 sujeitos), dificultando o cálculo do índice de herdabilidade, mas constatando uma concordância para JP de 9,8\% para dizigóticos contra 22,6\% para monozigóticos, evidenciando uma clara influência genética neste transtorno. (Eisen et al., 1998).

Slutske et al., em entrevista telefônica a 4497 pares de gêmeos do VET, demonstrou que fatores familiais respondiam por $66 \%$ da superposição entre os diagnósticos de Transtorno Antisocial de Personalidade (TAP) e JP, $86 \%$ da superposição entre TAP e Transtorno de Conduta da Infãncia (TC), e $61 \%$ da 
superposição entre CAA e JP, e que essa associação maior que o acaso seria parcialmente devida a um substrato genético comum às três (Slutske et al., 2001).

Também Potenza, a partir de entrevistas a participantes do VET, encontrou medidas elevadas de odds ratio para Depressão Maior (DM) associadas àquelas de JP, e essa associação se manteve significante após correção de variáveis sócio-demográficas e outras variáveis psiquiátricas (66\% da variância em JP e 41\% da variância em DM eram devidas a fatores genéticos, e 34\% da variância em JP e 59\% da variância em DM eram devidas a fatores ambientais), e descrevendo uma participação de fatores genéticos na ocorrencia da comorbidade entre JP e DM (Potenza et al., 2005).

Scherrer avaliou 1074 pares de gêmeos discordantes para JP, participantes do VET, associando trauma infantil ao desencadeamento posterior de comportamento de JP, encontrando uma associação com abuso infantil, negligência, presenciar ou sofrer violência física, tendo também constatado uma contribuição significante de fatores genéticos e familiares na associação entre exposição e um ou mais sintomas de JP (Scherrer et al., 2007).

\subsubsection{ESTUDOS GENETICO-MOLECULARES EM JOGO PATOLÓGICO:}

Do acima exposto, a investigação genética mostra-se um importante recurso de investigação biológica da predisposição aos achados neurofuncionais do JP. 
A partir dos trabalhos de Comings (1996) e Perez de Castro (1997), iniciou-se a investigação dos possíveis fatores genéticos de vulnerabilidade para comportamentos aditivos.

Comings et al (1996) encontrou, em estudo que incluiu 222 JP contra 714 controles, uma associação entre JP e o alelo 1 do DRD2 TaqIA.

Perez de Castro et al (1997), comparando 68 JP (47 homens e 21 mulheres) com 68 controles pareados para idade, gênero e grupo étnico, encontrou uma associação entre um alelo do DRD4 (exxon III) que contém 7 repetições e a ocorrência de JP em mulheres.

Comings et al (1997), usando amostra derivada da acima descrita (Comings et al., 1996), encontrou uma associação positiva entre JP e o alelo 1 da DRD1 Ddel.

Perez de Castro et al (1999), usando a mesma amostra acima descrita (Perez de Castro et al., 1997), encontrou uma associação entre o alelo curto (s) do 5HTTLPR e JP em homens.

Comings et al (1999), encontrou, na amostra acima (Comings et al., 1996), associação entre JP e alelos de repetição 5-8 e 7 do DRD4 (exon III).

Ibañez et al (1999), usando a mesma amostra que Perez de Castro et al. (1997), não encontrou associação entre JP e o polimorfismo no intron I do gene da tirosina hidroxilase. Em 2000, obteve uma associação do polimorfismo MAO-A/intron I (alelo de 4 repetições) e do polimorfismo MAO-B/promoter (alelo de 3 repetições) com JP em homens (Ibañez et al., 1999). 
Comings et al (2001) comparou 139 JP com 139 controles pareados em relação a 31 genes envolvidos na função da dopamina, serotonina, noradrenalina e GABA, tendo encontrado uma participação desses genes em menos de $2 \%$ da variância em JP.

Perez de Castro et al (2002), novamente utilizando-se da mesma amostra acima descrita (Perez de Castro et al, 1997), encontrou associação entre o alelo de 3 repetições da região promotora do gene da MAO-A, com formas mais graves de JP em homens.

Da Silva Lobo et al (2007), em amostra constando de 140 pares de irmãos discordantes para o diagnóstico de JP, encontrou uma associação entre o alelo T do polimorfismo DRD1 - 800 T/C nos JP.

Dado o caráter central da impulsividade no JP, e devido à íntima relação entre atividade serotonérgica e impulsividade, tem-se estudado diversos polimorfismos de genes envolvidos na regulação do sistema serotonérgico em sua associação com a impulsividade (Coccaro et al., 1998; Evans et al., 2000).

As duas abordagens gerais mais comuns são os estudos de ligação e os de associação. Os estudos de ligação utilizam marcadores de posição nos cromossomos para investigação de áreas que apresentam sinais de ligação com o fenótipo em estudo. Os estudos de associação procuram identificar genes de pequeno efeito, que isoladamente não são suficientes para desenvolver a doença, mas podem contribuir, juntamente com outros, para seu desencadeamento. Nos fenótipos complexos (em que os transtornos psiquiátricos são exemplo paradigmático), em que esses genes são prevalentes na população geral, os estudos genéticos têm-se utilizado principalmente dos estudos de associação. 
O gene do transportador de serotonina (SCL6A4) também tem sido associado a uma maior susceptibilidade à viragem maníaca por antidepressivos (Visser et al., 2005), e aos transtornos alimentares, tanto em relação à inserção / deleção dessa região promotora quanto do polimorfismo VNTR da região do intron 2, embora esses últimos resultados não tenham tido replicação inequívoca (Lauzurica et al., 2003).

Gerra et al. (2004), ao comparar 101 controles normais com 101 dependentes de heroína, tendo avaliado índices de agressividade impulsiva, trouxe evidências de uma associação entre o polimorfismo do promotor do gene transportador de serotonina (5HTTPLR) e risco mais elevado para o desenvolvimento de abuso de substâncias, particularmente em indivíduos impulsivos. O 5HTTLPR tem sido associado com vulnerabilidade aumentada para depressão, neuroticismo e autismo (Bradley et al., 2005). Sakado et al. (2004) também fornece indícios de associação entre diferenças genotípicas do 5-HTTPLR, tendo encontrado um aumento na pontuação global e na subescala "impulsividade por desatenção" em portadores do genótipo s/s, que seria menos funcional que os demais genótipos (1/s e 1/l), sugerindo assim uma maior propensão à impulsividade nesse genótipo. Lee et al. (2003), encontrou a mesma associação em estudo comparando dois grupos de homens coreanos (estudantes de medicina e prisioneiros) onde destacou diferenças na freqüência alélica 5-HTTLPR-s e 5-HTTLPR1, levantando a hipótese do alelo s ser um possível gene candidato para impulsividade naquela população.

Murphy et al. propõe que o 5-HTTLPR-s seja considerado como marcador genético para eficácia antidepressiva de inibidores seletivos de recaptação de serotonina (Murphy 
et al., 2004). Em estudo recente, Zalsman descreve uma variante do 5-HTTLPR-1, com uma troca $\mathrm{A} 22 \mathrm{G}$, onde a variante longa com o alelo $\mathrm{G}$ se comporta como uma variante curta, mantendo equivalência expressiva ao 5-HTTLPR-s, caracterizando uma terceira variação alélica que determinaria um efeito confundidor nos estudos anteriores (Zalsman et al., 2006).

O gene da 5HTT apresenta outro polimorfismo funcional além do 5HTTLPR, que é um VNTR em seu segundo intron (intron 2), e cuja associação a comportamento suicida tem sido estudada. Em estudo comparando suicidas e controles sadios croatas e eslavos não encontrou diferenças estatisticamente significativas na distribuição da freqüência alélica dos polimorfismos 5HTTLPR nem VNTR intron 2, porém revelou diferenças na análise de distribuição haplotípica, com um excesso do Haplótipo L10 entre os suicidas (Hranilovic et al., 2003).

Jernej et al. também demonstra influência dos polimorfismos do intron 2 na predisposição a comportamentos de auto-agressão e suicídio, em estudo que realizou , em que o alelo 1010 do intron-2 do 5HTT, com menor atividade transcricional ("atividade menor") mostra associação estatística significativa na atividade suicida.(Jernej et al., 2004).

Li et al. (2005) aponta para a associação entre um excesso de transmissão do alelo 861G do gene do receptor 5HT1-B em famílias de portadores de ADHD. Lappalainen et al. (1998) identificou um possível loco para predisposição a alcoolismo antisocial no 5HT1B, e Stefujl et al.(2004) descreve a mediação pelo 5HT1B no comportamento agressivo em camundongos, concluindo por seu envolvimento no controle da 
agressividade e impulsividade humanas (Stefujl et al, 2004, New et al., 2001; Bouwknecht et al., 2001).

Os receptores de serotonina do subgrupo 2 (5HT2) têm sido, como um todo, implicados como centralmente contributivos ao sistema de gratificação (Kenna et al., 2004), e associados a uma maior vulnerabilidade a manifestações depressivas em condições desfavoráveis (Jokela et al., 2007).

O gene do receptor suptipo 5HT2A também tem sido associado a um número de manifestações psicopatológicas de diversas naturezas: intolerância a efeitos colaterais de antidepressivos (Murphy et al, 2004), a perfis mais disfuncionais em pacientes deprimidos e pós-deprimidos (Abdolmaleky et al., 2005), a esquizofrenia (Bhagwagar et al., 2006), a traços impulsivos e comportamento anti-social em alcoólicos (Preuss et al., 2001; Hill et al., 2002).

Bjork et al. detectou uma pontuação maior no número de erros em testagem neuropsicológica nos homozigotos CC 5HT2A, bem como uma predisposição desses homozigotos a transtornos do humor ou abuso de substâncias, e levantando a hipótese do alelo T102C ser um marcador para uma redução da função regulatória serotonérgica no controle dos impulsos (Bjork et al., 2002).

Também Nomura et al. sugere a participação do 5HT2A no desencadeamento de comportamento impulsivo, genotipando sua região promotora, e encontrando uma associação estatística maior entre maior freqüência de erros comissionados em teste neuropsicológico nos portadores do alelo 1438A do que nos potadores do alelo $1438 \mathrm{G}$ (Nomura et al., 2006). Kennedy et al., (2006) encontrou associação entre traços de 
extroversão em portadores de Transtorno Borderline de Personalidade e o alelo C do T102C, e Prado-Lima (2004) encontrou associação entre o genótipo CC e o hábito ininterrupto de fumar (Prado Lima et al., 2004).

Os dados acima sugerem o caráter central da função serotonérgica na impulsividade.

No JP, características equivalentes às dependencias de substâncias (habituação, tolerância, progressão) apresentam-se claramente nos criterios diagnosticos e na história natural do transtorno. Estudos investigando o controle inibitorio cerebral e caracteristicas impulsivas em outros transtornos psiquiatricos sugerem que a investigação de genes envolvidos em etapas críticas do funcionamento do sistema serotonérgico poderá contribuir para esclarecer a etiopatogenia do JP. 


\section{OBJETIVOS:}

Investigar a associação entre polimorfismos de genes do sistema serotonérgico e de jogo patológico em pares de irmãos discordantes para este diagnóstico. 


\section{HIPÓTESES:}

Ho: Distribuição semelhante dos alelos dos loci investigados entre irmãos afetados e não-afetados;

H1: Diferença estatisticamente significante na distribuição dos alelos dos loci investigados entre os dois grupos. 


\section{MÉTODO}

\subsection{Casuística:}

Para o presente estudo, foram selecionados 140 pares de irmãos, discordantes para o diagnóstico de JP. O recrutamento foi realizado entre março de 2001 a fevereiro de 2003, a partir de sujeitos que procuraram tratamento no Ambulatório de Jogo Patológico e Outros Transtornos dos Impulsos (AMJO), do Departamento e Instituto de Psiquiatria, Hospital das Clínicas da Faculdade de Medicina da Universidade de São Paulo (IPq - HC-FMUSP). Os 140 pares de irmãos selecionados fizeram parte da tese de doutorado "Características de Personalidade e Jogo Patológico: análise comparativa de jogadores patológicos e seus irmãos”, defendida pela Dra. Daniela Sabbatini da Silva Lobo em 2005 (Lobo, 2005).

\subsubsection{Avaliação Clínica:}

As entrevistas diagnósticas nos pares de irmãos foram realizadas por psiquiatras (David Wilson, Daniela Lobo, Silvia Martins, Ana Maria Galetti e Hermano Tavares). O diagnóstico de JP foi realizado através de entrevista clínica utilizando os critérios diagnósticos do DSM-IV. Foram incluídos na amostra pares constituídos por um JP (DSM-IV $\geq 0$ ) e seu respectivo irmão não-JP (DSM-IV =0). Para a investigação de outros transtornos psiquiátricos foi utilizada uma entrevista psiquiátrica semi-estruturada traduzida para o português: Schedules for Clinical Assessment in Neuropsychiatry - 
SCAN (Andrade et al., 1998; Wing et al., 1990). A classificação diagnóstica foi obtida através de um programa especificamente desenhado para a análise computadorizada das entrevistas obtidas pelo SCAN denominado CATEGO (Wing et al., 1990). Optou-se pela utilização da classificação diagnóstica da CID-10. Os resultados da avaliação clínica fizerem parte da tese de doutorado "Características de Persoalidade e Jogo Patológico: análise comparativa de jogadores patológicos e seus irmãos”, defendida pela Dra. Daniela Sabbatini da Silva Lobo em 2005 (Lobo, 2005).

\subsubsection{Critérios de Inclusão e Exclusão:}

Além dos critérios diagnóstico supra citados, estabeleceu-se que os jogadores patológicos e respectivos irmãos incluídos possuíssem, no mínimo, cinco anos de educação formal e concordassem em completar o protocolo do estudo.

Foram excluídos sujeitos com história de qualquer episódio psicótico ou transtorno afetivo bipolar, bem como sujeitos com patologias clínicas (não psiquiátricas) instáveis ou demandando internação, doenças neurológicas (p. ex. acidente vascular cerebral, história de traumatismo craniano, doença de Parkinson) e retardo mental.

Nos casos em que o jogador possuía mais de um irmão que preenchia os critérios de inclusão, a seleção daquele que seria avaliado era feita de acordo com os seguintes critérios:

- $1^{\text {a }}$ opção: irmão de mesmo sexo e idade mais próxima do jogador;

- 2 a opção: irmão de mesmo sexo e com diferença de idade de até cinco anos; 
- $\quad 3^{\text {a }}$ opção: irmão de sexo oposto e com diferença de idade de até cinco anos;

- 4 a opção: irmão de mesmo sexo ou de sexo oposto com diferença de idade maior que cinco anos.

Durante o período em que os sujeitos foram avaliados, o candidato fazia parte da equipe do ambulatório (AMJO) e participou ativamente na entrevista e seleção da amostra.

Todos os sujeitos assinaram termo de consentimento após terem sido informados sobre os objetivos e procedimentos do estudo, conforme os requisitos estabelecidos pela Declaração de Helsinki. O estudo foi aprovado pelo Comitê de Ética em Pesquisa da Universidade de São Paulo.

\subsection{Extração de DNA:}

A extração de DNA foi realizada através do método de "salting out" (Miller et al., 1988). As amostras de DNA foram identificadas com sistema de código de barras e armazenadas em freezer $-80^{\circ} \mathrm{C}$, mantendo a confidencialidade dos dados e diminuindo as chances de erros de identificação.

Para a realização das genotipagens neste estudo foram obtidas alíquotas do DNA previamente armazenado. No entanto, o candidato recebeu treinamento na técnica de extração de DNA em outras amostras de sangue, pertencentes a outros projetos de pesquisa em curso à época. 


\subsection{Escolha de Polimorfismos para a Análise de Haplótipos:}

A partir da revisão da literatura, foram escolhidos 3 genes do sistema serotonérgico para a análise de haplótipos: o gene que codifica o transportador de serotonina (SLC6A4), o gene que codifica o receptor de serotonina subtipo 2A (HTR2A) e o gene que codifica o receptor de serotonina subtipo 1B (HTR1B).

As figuras 1, 2 e 3 apresentam a configuração haplotípica dos genes selecionados, à partir dos dados do projeto HapMap (www.hapmap.org) para caucasianos. O cálculo de desequilíbrio de ligação (LD) foi obtido através do programa Haploview versão 4.0 (Barrett et al., 2005). O gene SLC6A4 possui 54 single nucleotide polymorphisms (SNPs), o gene HTR2A possui 169 SNPs e o gene HTR1B possui seis SNPs genotipados pelo HapMap.

Em seguida, tag SNPs foram selecionados através do programa Haploview, utilizando um marcador para dois a três SNPs (aggressive tagging), com $\mathrm{r}^{2}>0.8 \mathrm{e}$ frequiência mínima para o alelo menos comum $(\mathrm{MAF}) \geq 0.01$. As figuras 3,4 e 5 apresentam a configuração haplotípica dos genes após a seleção dos tag SNPs. Para que fosse realizada uma análise de haplótipos que cobrisse toda a extensão dos genes selecionados, seria necessário genotipar 14 tag SNPs no SLC6A4, 40 tag SNPs no HTR2A e dois tag SNPs no HTR1B. No entanto, foi possível genotipar apenas SNPs cujos primers estavam disponíveis no laboratório. 
Figura 1: Single nucleotide polymorphisms (SNPs) no gene HTR2A, de acordo com os dados para população caucasiana do projeto HapMap (www.hapmap.org).

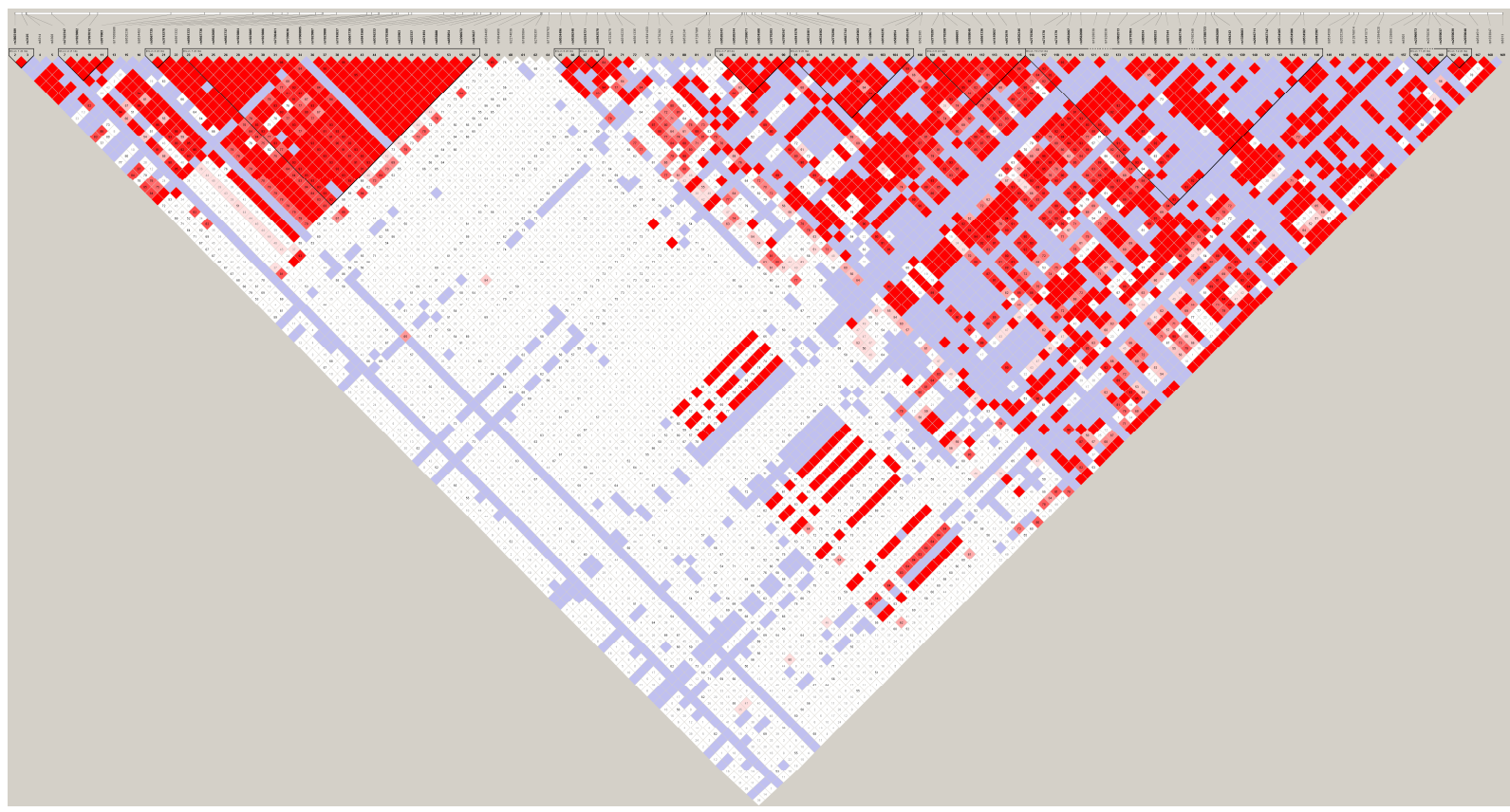


Figura 2: Single nucleotide polymorphisms (SNPs) no gene SLC6A4, de acordo com os dados para população caucasiana do projeto HapMap (www.hapmap.org).

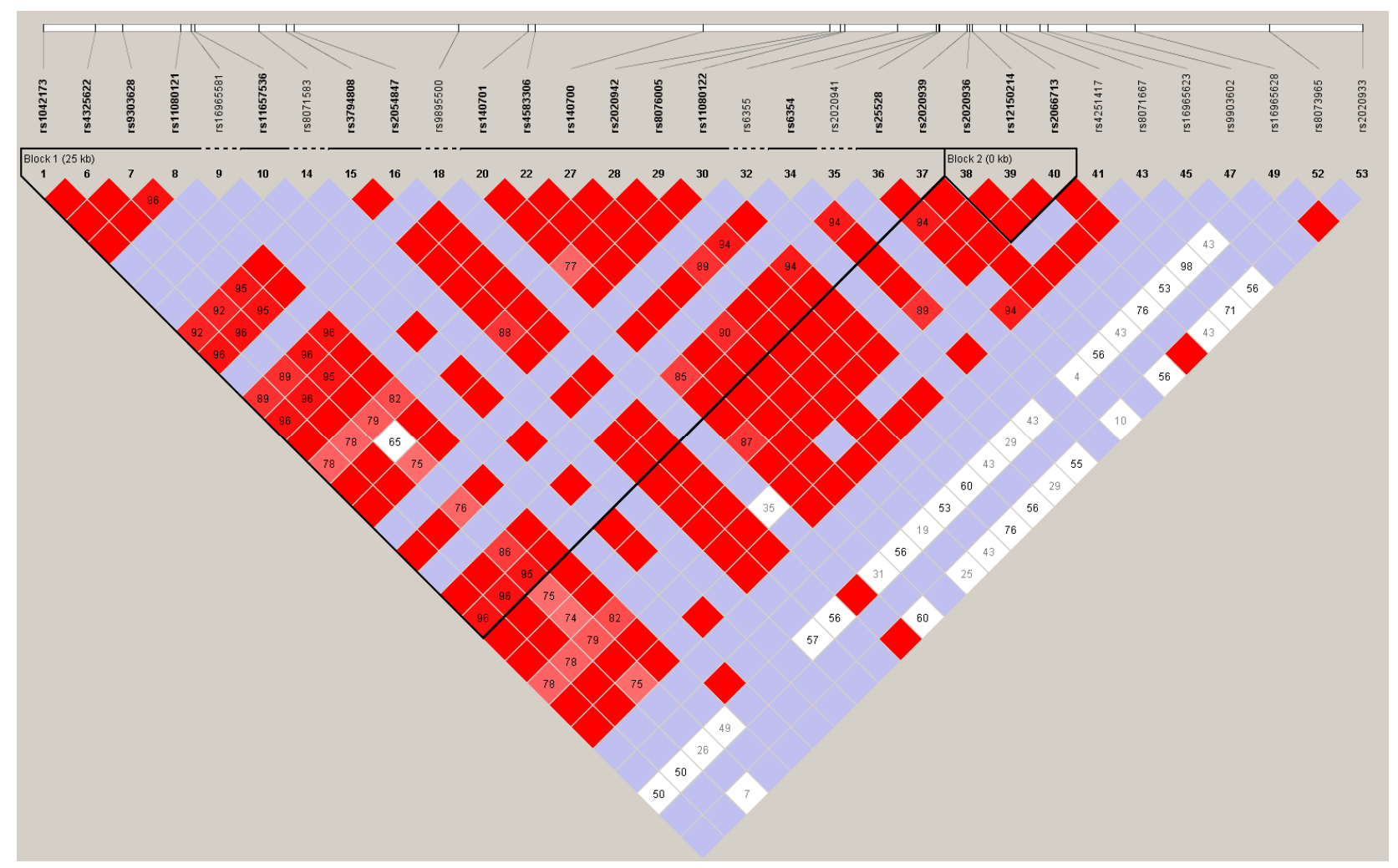


Figura 3: Single nucleotide polymorphisms (SNPs) no gene HTR1B, de acordo com os dados para população caucasiana do projeto HapMap (www.hapmap.org).

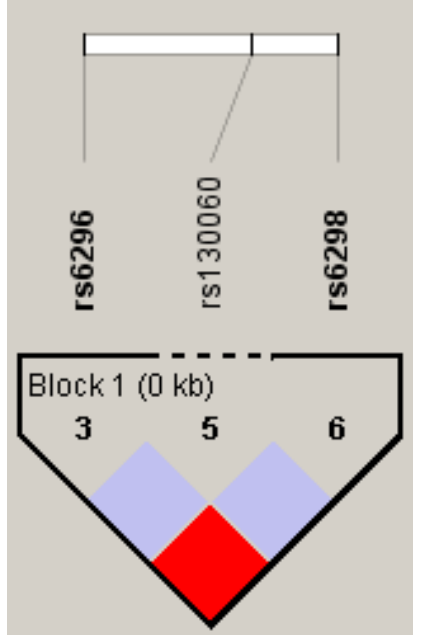


Figura 4: Single nucleotide polymorphisms (SNPs) selecionados (tagged SNPs) no gene HTR2A de acordo com os dados para população caucasiana projeto HapMap (www.hapmap.org).

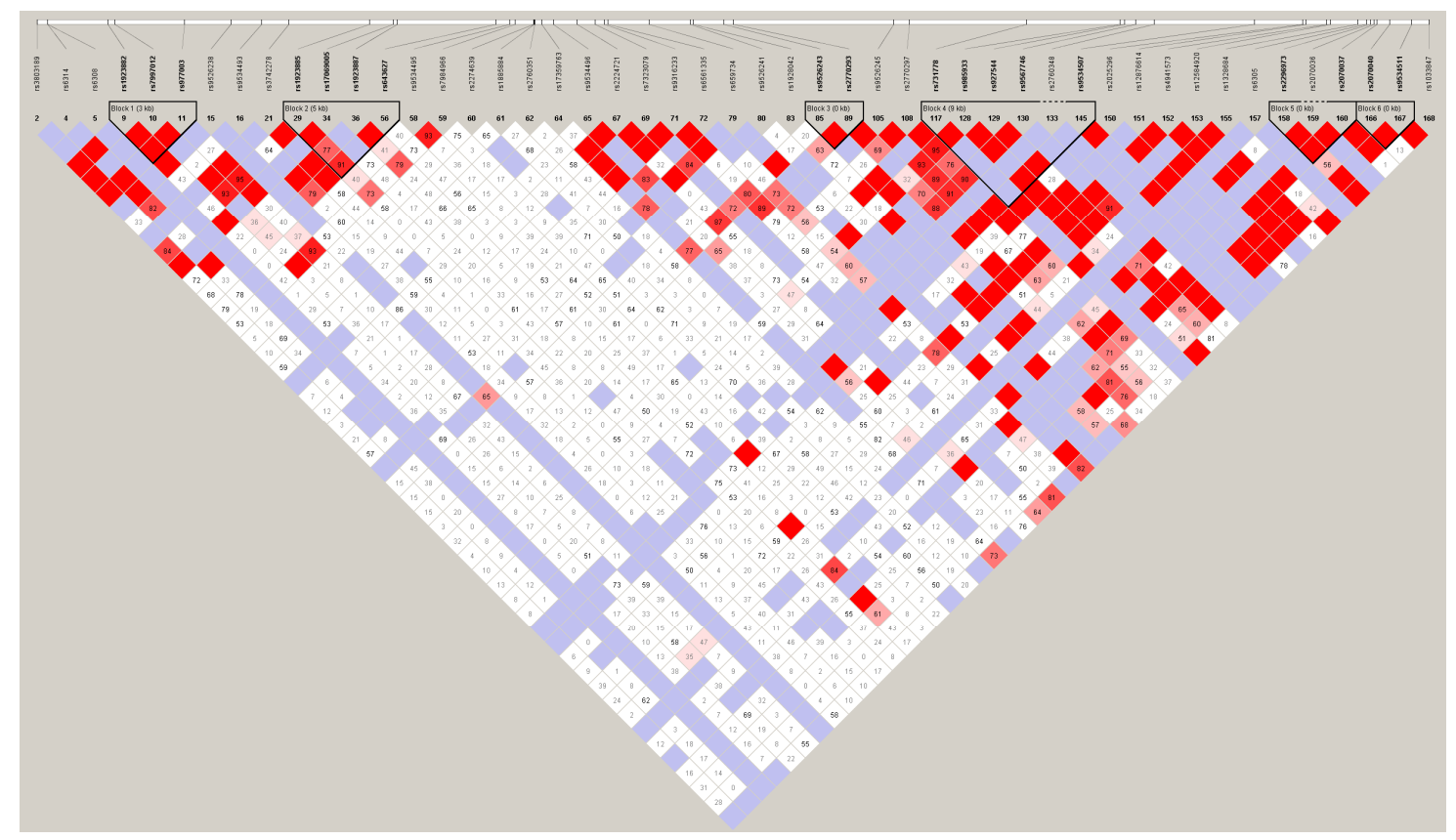


Figura 5: Single nucleotide polymorphisms (SNPs) no gene SLC6A4 selecionados (tagged SNPs) de acordo com os dados para população caucasiana do projeto HapMap (www.hapmap.org).

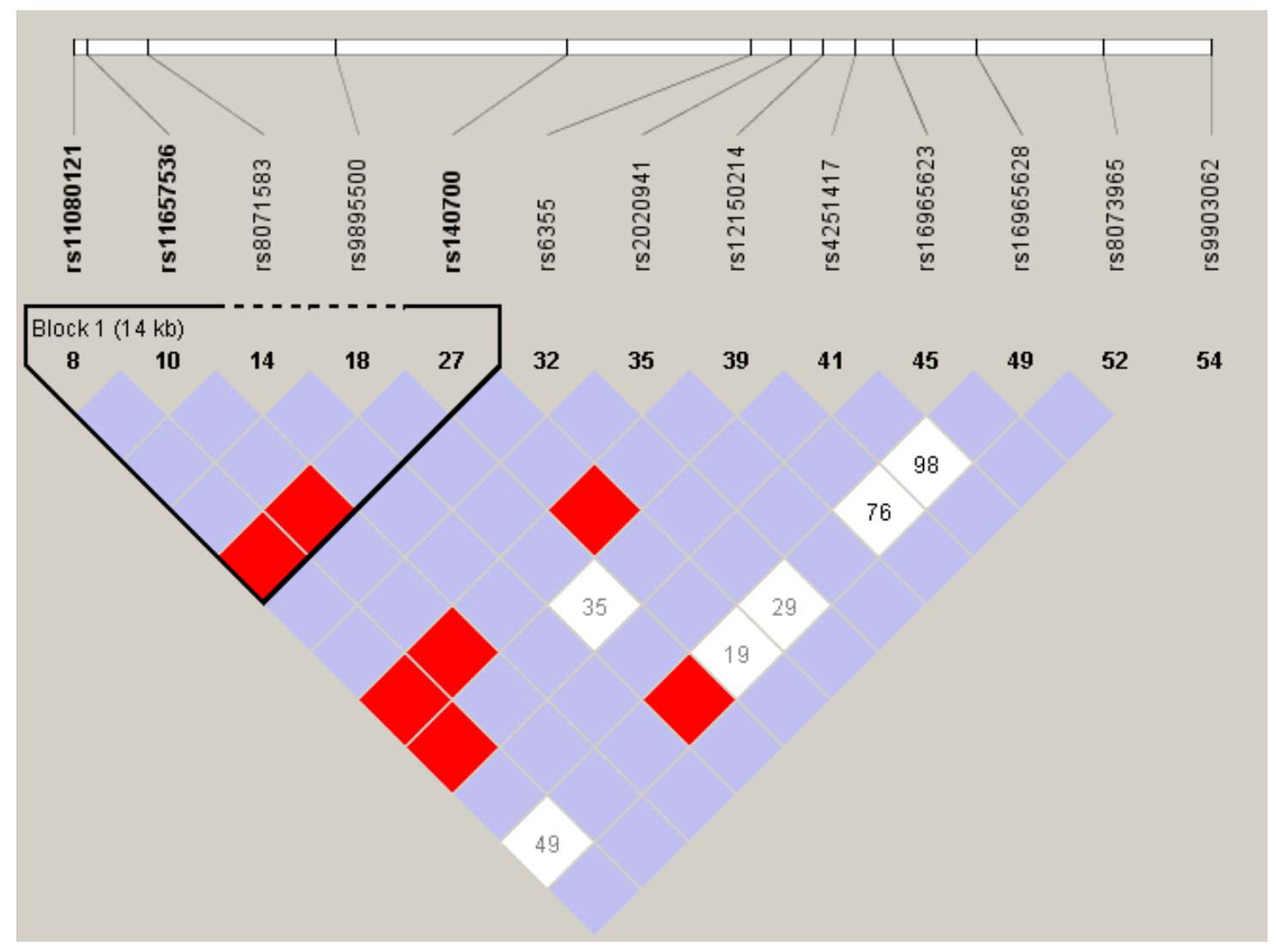


Figura 6: Single nucleotide polymorphisms (SNPs) no gene HTR1B selecionados (tagged SNPs) de acordo com os dados para população caucasiana do projeto HapMap (www.hapmap.org).

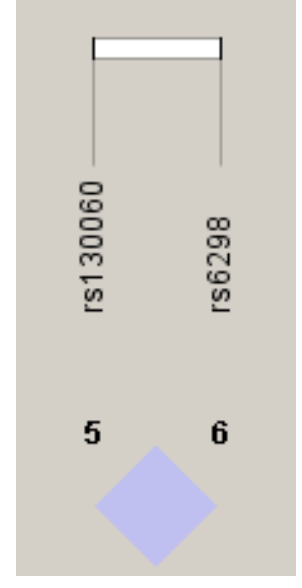




\subsection{GENOTIPAGEM:}

Foram selecionados polimorfismos em genes do sistema serotonérgico com demonstrada atividade funcional ou previamente associados às dependências de substâncias, jogo patológico ou a outros transtornos de controle dos impulsos. Todas as genotipagens foram realizadas pelo candidato, o qual recebeu treinamento e supervisão da equipe técnica do Laboratório de Genética do LIM-23 (Laboratório de Psicofarmacologia), IPq- HC-FMUSP.

A amplificação dos fragmentos polimórficos dos genes estudados foi obtida por técnica de reação em cadeia de polimerase (PCR). Para cada um dos polimorfismos estudados foram seguidos os protocolos específicos de PCR descritos a seguir. Os tamahos dos fragmentos foram estimados através de comparação com um marcador de tamanho de DNA (Ladder 100bp - Gibco). Amostras com genótipos ambíguos foram regenotipadas. Posteriormente, $10 \%$ da amostra foi selecionada aleatoriamente e regenotipada para controle de qualidade. A leitura dos genótipos foi feita sem que houvesse conhecimento sobre o diagnóstico dos sujeitos.

\subsubsection{Gene do Transportador de Serotonina 5HTTLPR (SLC6A4):}

Localiza-se no cromossomo 17q11.1-q12, sendo constituído por $31 \mathrm{~kb}$, e contendo 14 exons (Lesch et al., 1996). Foi genotipado o polimorfismo localizado na região promotora do gene, constituído por uma inserção/deleção de 44 bp - 5HTTLPR 
(Heils et al, 1996; Lesch et al., 1996). Este polimorfismo está localizado a cerca de $1 \mathrm{~kb}$ "upstream" do início do sítio de transcrição.

Foi seguido o protocolo de PCR conforme descrição de Cook et al. (Cook et al., 1997), utilizando 50 ๆg de DNA genômico, tampão de PCR Gibco $(2 \mu 1)$, PCR enhancer Invitrogen $(2,0 \mu 1)$, primer forward 5'-TGA ATG CCA GCA CCT AAC CC-3', primer reverse R1 5' - TTC TGG TGC CAC CTA GAC GC-3' (1,5 $\mu 1$ de cada), dATP, dTTP, dGTP e dCTP (200 $\mu \mathrm{M}$ de cada), $\mathrm{MgCl} 2(1,5 \mathrm{mM}, 1,5 \mu 1)$, e Taq polimerase Ampli-Taq ( $1 \mathrm{U})$. O ciclo de PCR consistiu em uma fase de desnaturação a $95^{\circ} \mathrm{C}$ por 3 minutos, uma fase de amplificação de 40 ciclos a $95^{\circ} \mathrm{C}$ por 30 segundos, $61^{\circ} \mathrm{C}$ por 30 segundos, $71^{\circ} \mathrm{C}$ por 1 minuto, e uma fase de extensão a $72^{\circ} \mathrm{C}$ por 10 minutos. Em seguida, os produtos de PCR foram incubados a $37^{\circ} \mathrm{C}$ por 12 horas com a enzima MspI $(0,5 \mu 1)$. Os fragmentos assim produzidos foram denominados:

- Alelo L (longo): 454bp

- Alelo S (curto): 406 bp

Os produtos de PCR foram separados por eletroforese em gel de agarose a 2,5\%, (100V, 1,5 hora).

\subsubsection{Gene do Receptor de Serotonina Subtipo 1B (HTR1B):}

$\mathrm{O}$ gene que codifica o receptor 5HT1B encontra-se no cromossomo 6q13(Mochizuki et al.,1992), consistindo de apenas 1 exon, não contendo nenhuma sequencia intrônica, com um quadro de leitura de 390 aminoácidos com sete regiões 
hidrofóbicas, típicas dos receptores acoplados à guanina (Demchyshyn et al., 1992).

Foi genotipado o polimorfismo contituído por uma substituição de guanina por citosina no nucleotídeo 861, denominado 5HT1B G861C (Lappalainen et al., 1995).

Na realização do PCR foram utilizados 50ๆg de DNA genômico, tampão de PCR Gibco, primer forward 5HT1B-A: 5' - GAA ACA GAC GCC CAA CAG GAC - 3', primer reverse 5HT1B-B: 5' -CCA GAA ACC GCG AAA GAA GAT- 3' (1,5 $\mu \mathrm{M})$, MgCl2, dATP, dTTP, dGTP e dCTP (200 $\mu \mathrm{M}$ de cada), Taq Polimerase Ampli-Taq (1U). A fase de desnaturação ocorreu a $95^{\circ} \mathrm{C}$ por 3 minutos, seguida de amplificação durante 30 ciclos de $95^{\circ} \mathrm{C}$ por 30 segundos, $57^{\circ} \mathrm{C}$ por 30 segundos, $72^{\circ} \mathrm{C}$ por 30 segundos, e uma extensão de $72^{\circ} \mathrm{C}$ por 7 minutos. Os produtos de PCR foram digeridos com as enzimas HinII e BSA durante 12 horas a $37^{\circ} \mathrm{C}$. Foi realizada eletroforese em gel de agarose $2,5 \%$ (100V, 1 hora) e visualizamos os seguintes alelos:

- Alelo longo: 548 bp

- Alelo curto: $406+142$ bp

\subsubsection{Gene do Receptor de Serotonina, subtipo 2A (HTR2A):}

O gene que codifica o receptor 5HT2A encontra-se no cromossomo 13q14-q21, consistindo de mais de $20 \mathrm{~kb}$, e consistindo de 3 exons e 2 introns, possuindo um comprimento de $20 \mathrm{~kb}$ (Chen et al., 1992). Foram genotipados os seguintes polimorfismos: 
- HTR2A (T102C): Localizado no exon 1, é constituído por uma substituição de timina por citosina no nucleotídeo 102 do gene (Warren et al., 1993). O protocolo de PCR (Warren et al., 1993) utilizou 150 ๆg de DNA genômico, tampão de PCR Gibco, primer forward 5' - GAC ACC AGG CTC TAC AGT AAT GAC - 3', primer reverse 5' - CGA CTG TCC AGT TAA ATG CAT CAGA- 3' (1,5 $\mu$ l de cada), $\mathrm{MgCl}_{2}$, dATP, dTTP, dGTP e dCTP (200 $\mu \mathrm{M}$ de cada), Taq Polimerase Ampli-Taq (1 U). A etapa de desnaturação realizada a $95^{\circ} \mathrm{C}$ durante 3 minutos, seguida de amplificação durante 35 ciclos de $94^{\circ} \mathrm{C}$ por 30 segundos, $61^{\circ} \mathrm{C}$ por 30 segundos, $72^{\circ} \mathrm{C}$ por 30 segundos, com uma extensão de $72^{\circ} \mathrm{C}$ por 7 minutos. Foi realizada digestão com a enzima de restrição MspI por 12 horas a $37^{\circ} \mathrm{C}$. Os produtos foram visualizados após eletroforese em gel de agarose a 2,5\% (100V, 1,5 hora). Os alelos visualizados são:

- Alelo 102T: 342bp

- Alelo 102C: $216+126$ bp

- HTR2A (C516T): Localizado no exon 2, resulta de uma substituição de citosina por timina no nucleotídeo 516 do gene (Arranz et al., 1995). O protocolo de PCR foi realizado com 100 ๆg de DNA genômico, tampão de PCR Gibco, primer forward 5'GGA TAG GGA TCC ATG TGC TC-3', primer reverse 5'-TGT GGT GGA TGG GAT TCT G -3' (1,5 $\mu 1$ de cada), $\mathrm{MgCl}_{2}$, dATP, dTTP, dGTP e dCTP (200 $\mu$ M de cada), Taq Polimerase Ampli-Taq (1U). A etapa de desnaturação realizada a $95^{\circ} \mathrm{C}$ durante 3 minutos, seguida de amplificação durante 40 ciclos de $94^{\circ} \mathrm{C}$ por 30 segundos, $61^{\circ} \mathrm{C}$ por 
30 segundos, $72^{\circ} \mathrm{C}$ por 30 segundos, com uma extensão de $72^{\circ} \mathrm{C}$ por 7 minutos. Foi realizada digestão com a enzima de restrição Sas96I por 12 horas a $37^{\circ} \mathrm{C}$. Os produtos foram visualizados após eletroforese em gel de agarose a 2,5\% (100V, 1,5 hora). Os alelos visualizados são:

- Alelo T516: 195 bp

- $\quad$ Alelo C516: $106+87$ bp

\subsection{ANÁLISE ESTATÍSTICA}

\subsubsection{Dados Sócio-Demográficos:}

Os dados sócio-demográficos obtidos nesta amostra foram analisados previamente pela Dra. Daniela Lobo (da Silva Lobo et al., 2007; Lobo, 2005). Os pares de irmãos foram comparados quanto à idade, sexo, situação econômica, escolaridade, etnia, estado civil, número de filhos, opção sexual e situação profissional. O SCAN foi utilizado para avaliação de comorbidades psiquiátricas presentes nos últimos 2 anos.

As comparações para as variáveis contínuas com distribuição normal foram feitas através do teste $\mathrm{t}$ de Student pareado e para as variáveis contínuas sem distribuição normal foi utilizado o teste de Wilcoxon para amostras pareadas. O teste $\chi^{2}$ de Pearson foi utilizado para variáveis categoriais com distribuição normal e o teste exato de Fisher para variáveis categoriais sem distribuição normal. A distribuição normal das variáveis foi verificada através dos testes de Kolmogorov- Smirnov e Shapiro-Wilk. 


\subsubsection{Polimorfismos do Sistema Serotonérgico:}

O cálculo de poder da amostra foi realizado através do programa QUANTO versão 1.1 (Goudriaan et al., 2004). O equilíbrio de Hardy-Weinberg foi verificado através do programa PEDSTATS (http://www.sph.umich.edu/csg/abecasis/PedStats/).

Tanto a análise univariada dos polimorfismos quanto a análise de associação de haplótipo foi realizada no programa UNPHASED versão 3.0.10 (Dudbridge, 2003; Dudbridge, 2006). Para o teste de associação de alelos e genótipos, o programa utiliza o teste de $\chi^{2}$ modificado por Dudbridge (2006) e compara o efeito de cada alelo / genótipo em relação ao alelo/ genótipo de referência (Dudbridge et al., 2006). Caso o alelo/ genótipo de referência esteja associado à variável dependente, o programa permite que outra referência seja especificada .

O teste de associação de haplótipos verifica a diferença de cada um dos haplótipos comparada ao agrupamento dos haplótipos restantes. A hipótese de nulidade para a obtenção do valor de odds ratio no teste de associação de haplótipos é de que nenhum dos marcadores testados contribui para o aumento do risco de ocorrência da variável dependente (Dudbridge et al., 2006).

A análise estatística que envolve os dados de genética molecular foi realizada em colaboração com a Dra. Daniela Lobo, do Center for Addiction and Mental Health na Universidade de Toronto, Canadá. 


\section{RESULTADOS}

\subsection{Dados Sócio-Demográficos:}

Os 140 pares de irmãos apresentam a seguinte distribuição em relação ao sexo: 37 jogador masculino/ irmão masculino, 33 jogador masculino/ irmão feminino, 37 jogador feminino/ irmão feminino, 33 jogador feminino/ irmão masculino. Com relação à etnia, $78 \%$ dos indivíduos foram classificados como brancos, $19 \%$ como pardos e $2 \%$ como negros e $1 \%$ como amarelos, conforme descrito em estudo anterior (Lobo, 2005).

A tabela 1(1a e 1b) apresenta os resultados das comparações de dados sóciodemográficos entre os dois grupos, aqui reproduzida com autrorização da autora (Lobo, 2005). 
Tabela 1a: Dados sócio-demográficos de jogadores patológicos comparados ao irmão não-jogador - variáveis quantitativas.

\begin{tabular}{|c|c|c|c|c|}
\hline Características & Média \pm DP & Mediana & $p($ dep) & $\overline{p(\text { indep) }}$ \\
\hline $\begin{array}{l}\text { Idade (anos) } \\
\text { Jogadores Patológicos }(n=140) \\
\text { Irmãos Não-Jogadores }(n=140)\end{array}$ & $\begin{array}{l}40,55 \pm 8,85 \\
40,22 \pm 9,82\end{array}$ & $\begin{array}{l}41 \\
40\end{array}$ & 0,485 & 0,769 \\
\hline $\begin{array}{l}\text { Anos de Educação Formal } \\
\text { Jogadores Patológicos }(n=140) \\
\text { Irmãos Não-Jogadores }(n=140)\end{array}$ & $\begin{array}{l}12,71 \pm 3,50 \\
13,16 \pm 3,90\end{array}$ & $\begin{array}{l}13 \\
13\end{array}$ & $0,103^{\S}$ & $0,312^{\S}$ \\
\hline $\begin{array}{l}\text { Indicador de Classe } \\
\text { Econômica }(1,5-15) \\
\text { Jogadores Patológicos }(n=140) \\
\text { Irmãos Não-Jogadores }(n=140)\end{array}$ & $\begin{array}{l}5,32 \pm 2,57 \\
6,18 \pm 3,66\end{array}$ & $\begin{array}{l}5 \\
5,33\end{array}$ & $0,084^{\S}$ & $0,091^{\S}$ \\
\hline $\begin{array}{l}\text { Número de Filhos } \\
\text { Jogadores Patológicos (n=140) } \\
\text { Irmãos Não-Jogadores ( } \mathrm{n}=140)\end{array}$ & $\begin{array}{l}1,45 \pm 1,27 \\
1,39 \pm 1,53\end{array}$ & $\begin{array}{l}1,5 \\
1\end{array}$ & $0,286^{\S}$ & $0,434^{\S}$ \\
\hline
\end{tabular}

p (dep): nível descritivo do teste t de Student pareado

$\mathrm{p}^{\S}$ (dep): nível descritivo do teste de Wilcoxon para amostras pareadas

p (indep): nível descritivo do teste t de Student para amostras independentes

$\mathrm{p}^{\S}$ (indep): nível descritivo do teste de Mann_Whitney 
Tabela 1b: Dados sócio-demográficos de jogadores patológicos comparados ao irmão não-jogador - variáveis quantitativas.

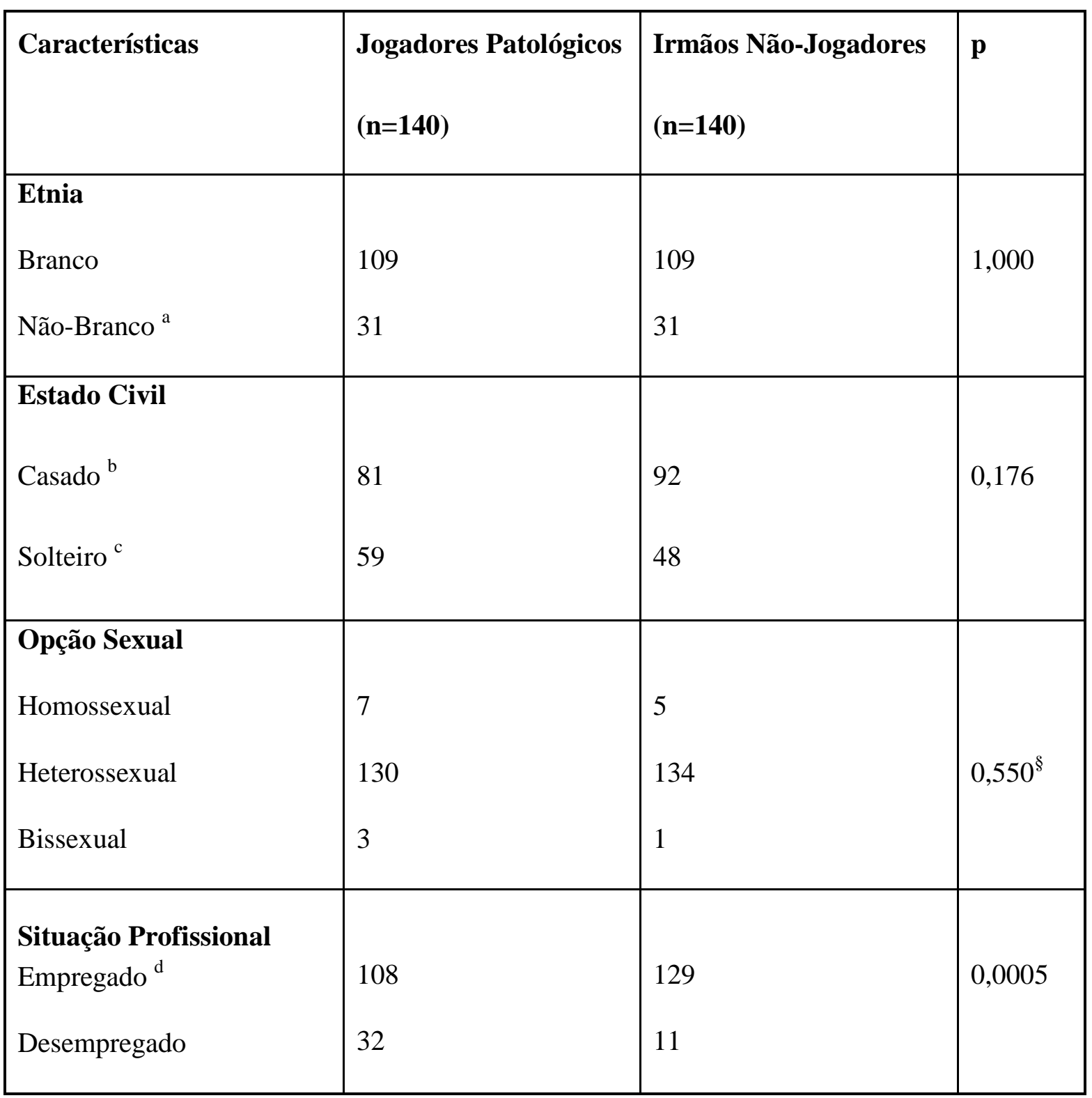

${ }^{\mathrm{a}}$ Inclui pardos, negros e amarelos.

${ }^{\mathrm{b}}$ Inclui legalmente casados e em concubinato.

${ }^{\mathrm{c}}$ Inclui solteiros, viúvos, separados e divorciados.

${ }^{\mathrm{d}}$ Inclui autônomos, donas de casa e aposentados.

p: nível descritivo do teste qui-quadrado de Pearson / $\mathrm{p}^{\S}$ : nível descritivo do teste exato de Fisher 


\subsection{Comorbidades Psiquiátricas:}

A tabela 2 (2a e $2 b)$ apresenta os resultados referentes às comorbidades psiquiátricas, comparando-se o grupo de jogadores patológicos com os irmãos nãojogadores. As tabelas têm como variável resposta a variável jogo (jogador/ irmão nãojogador). As tabelas aqui apresentadas foram reproduzidas com autorização da autora (Lobo, 2005). 
Tabela 2a: Comparação de comorbidades psiquiátricas - jogadores e irmãos nãojogadores.

\begin{tabular}{|c|c|c|c|c|}
\hline $\begin{array}{l}\text { Comorbidades } \\
\text { Psiquiátricas }\end{array}$ & $\begin{array}{l}\text { Jogadores } \\
\text { Patológicos } \\
\text { n (\%) } \\
\end{array}$ & $\begin{array}{l}\text { Irmãos Não } \\
\text { Jogadores } \\
\text { n }(\%) \\
\end{array}$ & $\begin{array}{l}\text { Total } \\
\text { n }(\%)\end{array}$ & $\mathbf{p}$ \\
\hline $\begin{array}{l}\text { Transtornos Bipolares } \\
\text { sim } \\
\text { Não }\end{array}$ & $\begin{array}{l}8(100,0) \\
132(48,5) \\
\end{array}$ & $\begin{array}{l}0(0,0) \\
140(51,5)\end{array}$ & $\begin{array}{l}8(2,9) \\
272(97,1)\end{array}$ & $0,0070^{\S}$ \\
\hline $\begin{array}{l}\text { Transtorno Depressivo } \\
\text { sim } \\
\text { Não }\end{array}$ & $\begin{array}{l}94(78,3) \\
46(28,8)\end{array}$ & $\begin{array}{l}26(21,7) \\
114(71,3)\end{array}$ & $\begin{array}{l}120(42,9) \\
160(57,1)\end{array}$ & $<0,0001$ \\
\hline $\begin{array}{l}\text { Transtorno do Pânico } \\
\text { sim } \\
\text { Não }\end{array}$ & $\begin{array}{l}8(80,0) \\
132(48,9)\end{array}$ & $\begin{array}{l}2(20,0) \\
138(51,1)\end{array}$ & $\begin{array}{l}10(3,6) \\
270(96,4)\end{array}$ & 0,0533 \\
\hline $\begin{array}{l}\text { Fobia social e específica } \\
\text { sim } \\
\text { Não }\end{array}$ & $\begin{array}{l}46(56,1) \\
94(47,5)\end{array}$ & $\begin{array}{l}36(43,9) \\
104(52,5)\end{array}$ & $\begin{array}{l}82(29,3) \\
198(70,7)\end{array}$ & 0,1891 \\
\hline $\begin{array}{l}\text { Transtornos Fóbico- } \\
\text { Ansiosos }{ }^{1} \\
\text { sim } \\
\text { Não }\end{array}$ & $\begin{array}{l}51(58,6) \\
88(45,8)\end{array}$ & $\begin{array}{l}36(41,4) \\
104(54,2)\end{array}$ & $\begin{array}{l}87(31,2) \\
192(68,8)\end{array}$ & 0,0478 \\
\hline $\begin{array}{l}\text { Transtorno Obsessivo- } \\
\text { Compulsivo } \\
\text { sim } \\
\text { Não } \\
\end{array}$ & $\begin{array}{l}9(52,9) \\
131(49,8) \\
\end{array}$ & $\begin{array}{l}8(47,1) \\
132(50,2)\end{array}$ & $\begin{array}{l}17(6,1) \\
263(93,9)\end{array}$ & 0,8024 \\
\hline $\begin{array}{l}\text { Transtornos de } \\
\text { Ajustamento e Reação } \\
\text { Aguda ao Estresse } \\
\text { sim } \\
\text { Não }\end{array}$ & $\begin{array}{l}4(13,3) \\
136(54,4)\end{array}$ & $\begin{array}{l}26(86,7) \\
114(45,6)\end{array}$ & $\begin{array}{l}30(10,7) \\
250(89,3)\end{array}$ & $<0,0001$ \\
\hline $\begin{array}{l}\text { Dependência de } \\
\text { Estimulantes } \\
\text { sim } \\
\text { Não }\end{array}$ & $\begin{array}{l}5(100,0) \\
135(49,1)\end{array}$ & $\begin{array}{l}0 \\
140(50,9) \\
\end{array}$ & $\begin{array}{l}5(1,8) \\
275(98,2) \\
\end{array}$ & $0,0603^{\S}$ \\
\hline
\end{tabular}

$\mathrm{p}$ : teste qui-quadrado de Pearson / $\mathrm{p}^{\S}$ : teste exato de Fisher

${ }^{1}$ Inclui: fobias social e específicas. 
Tabela 2b: Comparação de comorbidades psiquiátricas - jogadores e irmãos nãojogadores.

\begin{tabular}{|c|c|c|c|c|}
\hline Comorbidades Psiquiátricas & $\begin{array}{l}\text { Jogadores Patológicos } \\
\text { n }(\%)\end{array}$ & $\begin{array}{l}\text { Irmãos Não-Jogadores } \\
\text { n (\%) }\end{array}$ & $\begin{array}{l}\text { Total } \\
\text { n }(\%)\end{array}$ & $\mathbf{p}$ \\
\hline $\begin{array}{l}\text { Uso de Nicotina ao Longo da } \\
\text { Vida } \\
\text { sim } \\
\text { Não }\end{array}$ & $\begin{array}{l}119(65,0) \\
21(21,6)\end{array}$ & $\begin{array}{l}64(35,0) \\
76(78,4)\end{array}$ & $\begin{array}{l}183(65,4) \\
97(36,4)\end{array}$ & $<0,0001$ \\
\hline $\begin{array}{l}\text { Uso de Nicotina Atualmente } \\
\text { sim } \\
\text { Não }\end{array}$ & $\begin{array}{l}107(75,9) \\
33(23,7)\end{array}$ & $\begin{array}{l}34(24,1) \\
106(76,3)\end{array}$ & $\begin{array}{l}141(50,4) \\
139(49,6)\end{array}$ & $<0,0001$ \\
\hline $\begin{array}{l}\text { Dependência de Nicotina ao } \\
\text { Longo da Vida } \\
\text { sim } \\
\text { Não }\end{array}$ & $\begin{array}{l}112(66,7) \\
28(25,0)\end{array}$ & $\begin{array}{l}56(33,3) \\
84(75,0)\end{array}$ & $\begin{array}{l}168(60,0) \\
112(40,0) \\
\end{array}$ & $<0,0001$ \\
\hline $\begin{array}{l}\text { Dependência de Nicotina } \\
\text { Atualmente } \\
\text { sim } \\
\text { Não }\end{array}$ & $\begin{array}{l}104(76,5) \\
36(25,0)\end{array}$ & $\begin{array}{l}32(23,5) \\
108(75,0)\end{array}$ & $\begin{array}{l}136(48,6) \\
144(51,4)\end{array}$ & $<0,0001$ \\
\hline $\begin{array}{l}\text { Dependência de Álcool } \\
\text { sim } \\
\text { Não }\end{array}$ & $\begin{array}{l}18(85,7) \\
122(47,1)\end{array}$ & $\begin{array}{l}3(14,3) \\
137(52,9)\end{array}$ & $\begin{array}{l}21(7,5) \\
259(92,5)\end{array}$ & 0,0007 \\
\hline $\begin{array}{l}\text { Dependência de Opióides } \\
\text { sim } \\
\text { Não }\end{array}$ & $\begin{array}{l}0 \\
140(50,0)\end{array}$ & $\begin{array}{l}0 \\
140(50,0)\end{array}$ & $\begin{array}{l}0 \\
280(100,0)\end{array}$ & - \\
\hline $\begin{array}{l}\text { Dependência de Cannabis } \\
\text { sim } \\
\text { Não }\end{array}$ & $\begin{array}{l}1(25,0) \\
139(50,4)\end{array}$ & $\begin{array}{l}3(75,0) \\
137(49,6)\end{array}$ & $\begin{array}{l}4(1,4) \\
276(98,6)\end{array}$ & $0,6223^{\S}$ \\
\hline $\begin{array}{l}\text { Dependência de Sedativose } \\
\text { Hipnóticos } \\
\text { sim } \\
\text { Não }\end{array}$ & $\begin{array}{l}1(50,0) \\
139(50,0)\end{array}$ & $\begin{array}{l}1(50,0) \\
139(50,0)\end{array}$ & $\begin{array}{l}2(0,7) \\
278(99,3)\end{array}$ & $1,0000^{\S}$ \\
\hline $\begin{array}{l}\text { Dependência de Cocaína } \\
\text { sim } \\
\text { Não }\end{array}$ & $\begin{array}{l}2(50,0) \\
138(50,0)\end{array}$ & $\begin{array}{l}2(50,0) \\
138(50,0)\end{array}$ & $\begin{array}{l}4(1,4) \\
276(98,6)\end{array}$ & $1,0000^{\S}$ \\
\hline $\begin{array}{l}\text { Dependência de Estimulantes } \\
\text { sim } \\
\text { Não }\end{array}$ & $\begin{array}{l}5(100,0) \\
135(49,1)\end{array}$ & $\begin{array}{l}0 \\
140(50,9)\end{array}$ & $\begin{array}{l}5(1,8) \\
275(98,2)\end{array}$ & $0,0603^{\S}$ \\
\hline
\end{tabular}




\subsection{Polimorfismos do Sistema Serotonérgico:}

Utilizando o modelo aditivo, a amostra possui de 70 a $80 \%$ de poder de detecção de associação alélica tendo como parâmetros: $\alpha$ 0.05, p bicaudal, odds ratio $2.0 \mathrm{e}$ freqüência do alelo menos comum (MAF - minor allele frequency) de 0.20 a 0.40 . A MAF foi determinada através das freqüências esperadas para caucasianos descritas no National Center for Biotechnology Information (http://www.ncbi.nlm.nih.gov/) ou nas publicações em que o polimorfismo foi descrito. Por exemplo, a freqüência esperada para o HTR2A alelo 102C é de 45\% (Erdmann et al., 1996) e para o HTTLPR alelo S é de 43\% (Lesch et al., 1996).

O teste de equilíbrio de Hardy-Weinberg foi verificado em JP e nos irmãos separadamente. Todos os polimorfismos analisados estavam em equilíbrio em ambos grupos.

As tabelas 3-6 apresentam os resultados dos testes de associação para os polimorfismos investigados. A tabela 7 apresenta os resultados para o teste de associação para o haplótipo HTR2A (T102C)_(C516T), obtido com o método "sliding window". 
Tabela 3. Teste de associação alélica e genotípica para o polimorfismo 5HTTLPR em 140 pares de irmãos discordantes para o diagnóstico de jogo patológico, UNPHASED 3.0.10.

\begin{tabular}{|c|c|c|c|c|c|}
\hline Alelos & $\begin{array}{l}\text { JP } \\
\mathbf{N}(\%)\end{array}$ & $\begin{array}{l}\text { INJ } \\
\text { n (\%) }\end{array}$ & OR (95\% IC) & $\chi^{2}$ & $\mathbf{p}$ \\
\hline L (longo) & $111(53)$ & $109(55)$ & $0.8(0.6-1.2)$ & \multirow[t]{2}{*}{0.04} & \multirow[t]{2}{*}{0.83} \\
\hline S (curto) & $97(47)$ & $90(45)$ & $1.1(0.4-3)$ & & \\
\hline $\mathbf{L} / \mathrm{L}$ & $28(27)$ & $27(28)$ & $0.8(0.2-3)$ & 0.01 & 0.91 \\
\hline L/S & $55(53)$ & $55(54)$ & $0.8(0.2-3)$ & 0.13 & 0.72 \\
\hline $\mathbf{S} / \mathbf{S}$ & $21(20)$ & $17(18)$ & $1.2(0.5-2.7)$ & 0.20 & 0.65 \\
\hline
\end{tabular}


Tabela 4. Teste de associação alélica e genotípica para o polimorfismo HTR1B G861C em 140 pares de irmãos discordantes para o diagnóstico de jogo patológico, UNPHASED 3.0.10.

\begin{tabular}{|c|c|c|c|c|c|}
\hline Alelos & $\begin{array}{l}\mathbf{J P} \\
\mathbf{N}(\%)\end{array}$ & $\begin{array}{l}\text { INJ } \\
\text { n (\%) }\end{array}$ & OR (95\% IC) & $\chi^{2}$ & $\mathbf{p}$ \\
\hline G & $194(70)$ & 197(72) & $0.9(0.6-1.3)$ & \multirow[t]{2}{*}{0.35} & \multirow[t]{2}{*}{0.55} \\
\hline $\mathbf{C}$ & $82(30)$ & $76(28)$ & $1.2(0.4-3.7)$ & & \\
\hline G/G & $72(52)$ & $73(53)$ & $1.1(0.2-5.3)$ & 0.47 & 0.49 \\
\hline $\mathrm{C} / \mathrm{G}$ & $50(36)$ & $47(35)$ & $1.1(0.2-5.3)$ & 0.28 & 0.59 \\
\hline $\mathrm{C} / \mathrm{C}$ & $16(12)$ & $16(12)$ & $1(0.5-2.2)$ & 0.02 & 0.88 \\
\hline
\end{tabular}


Tabela 5. Teste de associação alélica e genotípica para o polimorfismo HTR2A T102C em 140 pares de irmãos discordantes para o diagnóstico de jogo patológico, UNPHASED 3.0.10.

\begin{tabular}{|c|c|c|c|c|c|}
\hline Alelos & $\begin{array}{l}\text { JP } \\
\mathbf{N}(\%)\end{array}$ & $\begin{array}{l}\text { INJ } \\
\text { n (\%) }\end{array}$ & OR (95\% IC) & $\chi^{2}$ & $\mathbf{p}$ \\
\hline $\mathbf{C}$ & $90(64)$ & $77(55)$ & & \multirow[t]{2}{*}{5.6} & \multirow[t]{2}{*}{0.01} \\
\hline $\mathbf{T}$ & $50(36)$ & $58(42)$ & $0.6(0.2-1.6)$ & & \\
\hline $\mathrm{C} / \mathrm{C}$ & $59(42)$ & $49(35)$ & () & 4.9 & 0.02 \\
\hline $\mathrm{C} / \mathrm{T}$ & $62(44)$ & $64(46)$ & () & 1.3 & 0.26 \\
\hline $\mathbf{T} / \mathbf{T}$ & $19(14)$ & $27(19)$ & $0.5(0.1-2.9)$ & 2.1 & 0.15 \\
\hline
\end{tabular}


Tabela 6. Teste de associação alélica e genotípica para o polimorfismo HTR2A C516T em 140 pares de irmãos discordantes para o diagnóstico de jogo patológico, UNPHASED 3.0.10.*

\begin{tabular}{|c|c|c|c|c|c|}
\hline Alelos & $\begin{array}{l}\text { JP } \\
\mathbf{N}(\%)\end{array}$ & $\begin{array}{l}\text { INJ } \\
\text { n (\%) }\end{array}$ & OR $(95 \%$ IC $)$ & $\chi^{2}$ & $\mathbf{p}$ \\
\hline $\mathbf{C}$ & $200(97)$ & $200(99)$ & $0.5(0.1-2)$ & \multirow[t]{2}{*}{0.08} & \multirow[t]{2}{*}{0.77} \\
\hline $\mathbf{T}$ & $6(3)$ & $3(1)$ & $2.0(0.5-8)$ & & \\
\hline $\mathrm{C} / \mathrm{C}$ & $98(95)$ & $97(95)$ & $0.8(0.2-3)$ & 0.67 & 0.41 \\
\hline $\mathbf{C} / \mathbf{T}$ & $4(4)$ & $5(5)$ & $0.8(0.2-3)$ & 1.53 & 0.22 \\
\hline $\mathbf{T} / \mathbf{T}$ & - & - & - & - & - \\
\hline
\end{tabular}

* Somente genótipos com frequiência $\geq 5$ são incluídos na análise. 
Tabela 7. Teste de associação de haplótipos, método "sliding windows", para os polimorfismos HTR2A (C516T) e (T102C) em 140 pares de irmãos discordantes para o diagnóstico de jogo patológico, UNPHASED 3.0.10**

\begin{tabular}{|l|l|l|l|l|l|}
\hline $\begin{array}{l}\text { Haplótipo } \\
\text { (C516T)_(T102C) }\end{array}$ & JP $(\%)$ & INJ & OR (95\% IC) & $\mathbf{X}^{\mathbf{2}}$ & $\mathbf{p}$ \\
\cline { 1 - 4 } 516C_102C & $90(64)$ & $77(55)$ & $1.4(0.8-2.2)$ & 4.65 & 0.03 \\
\cline { 1 - 4 } 516C_102T & $50(36)$ & $58(42)$ & $0.6(0.2-1.6)$ & & \\
\hline
\end{tabular}

* Somente os haplótipos mais prováveis são analisados. 


\section{DISCUSSÃO:}

O presente trabalho investigou os loci 5HTT, HTR1B, HTR2AT102C e 5HT2AC516T em 140 pares de irmãos discordantes para o diagnóstico de Jogo Patológico. Trata-se de uma das maiores amostras utilizadas em genética molecular para esse fenótipo, além de constituir-se num estudo pioneiro em meio brasileiro.

É importante que se tenha estudos genéticos conduzidos no Brasil utilizando pares de irmãos, por vezes em preferência à população-geral, porque tais estudos tendem a reduzir de maneira importante o efeito de estratificação étnica que decorre da ampla miscigenação de povos que caracteriza nossa população, e que, freqüentemente, falseiam associações.

\subsection{Características Sócio-Demográficas}

Os grupos apresentaram grande semelhança nas características sóciodemográficas, mostrando-se, como um todo, bastante homogêneos nestas características.

Uma vez que a característica de impulsividade pode variar em sua medida com o progredir da idade (Pfohl et al.,1999; Deakin et al., 2004), a amostra já havia sido selecionada levando-se em conta uma diferença de idade máxima de 5 anos entre os JP e seus irmãos. 
Do ponto-de-vista da escolaridade, não houve diferença significativa entre ambos grupos, embora tenha havido uma maior frequiência de desemprego em JP do que em seus irmãos. Esse fato sugere que esse desemprego seja devido pelo JP, pois uma das características do mesmo é priorizar o hábito de apostar em relação a qualquer outra atividade, inclusive a laboral (Beaudoin e Cox, 1999), conforme discutido em estudo anterior (Lobo, 2005).

\subsection{Comorbidade Psiquiátrica}

A análise univariada evidencia as altas taxas de comorbidade psiquiátrica em JP, estando de acordo com resultados de estudos anteriores (Crockford e El-Guebaly, 1998; Petry, 2000. Raylu e Oei, 2002; Martins, 2003; Martins et al., 2004; Dannon et al., 2006; Mason e Arnold, 2007; Kruedelbach et al.,2006; Scherrer et al., 2007). Diversos estudos abordam a associação entre diversos transtornos psiquiátricos ou sua intensificação sintomática e o JP, sugerindo que ambos compartilhem a mesma vulnerabilidade genética (Desai, 2008; Slutske et al., 2000; Stewart et al., 2003; Petry, 2005; Pietrzak RH et al., 2007).

O estudo realizado por Lobo (2005) revela que a maioria $(n=94)$ dos JP apresentou diagnóstico de transtorno depressivo e freqüência significativamente maior de tentativas de suicídio em comparação aos irmãos, corroborando achados de estudos anteriores (Crockford e el-Guebaly, 1998; Black e Moyer, 1988; Raylu e Oei, 2002, 
Tavares et al., 2003; Martins et al., 2004; Stuhldreher et al., 2007), e ressaltando a importância do diagnóstico e tratamento desta comorbidade.

Em contrapartida, a frequiência de transtornos de ajustamento e reação aguda ao estresse entre os irmãos foi significativamente maior em comparação aos JP. Lobo (2005) tambem sugere que os irmãos poderiam ter respostas emocionais e reações com melhor potencial adapatativo do que os JP.

A associação entre dependência de nicotina e JP também foi verificada em outros estudos, sendo discutido que as altas taxas de comorbidade sejam decorrentes de uma vulnerabilidade comum ou do estímulo ao uso de nicotina nos ambientes de jogo (Trout et al., 1998; Trotter et al., 2002; Potenza et al., 2004; Mason e Arnold, 2007).

\subsection{Investigação da Associação entre Jogo Patológico e Genes Envolvidos na Atividade Serotonérgica Cerebral}

Estudos anteriores investigaram a associação entre Jogo Patológico e polimorfismos de genes associados a neurotransmissores ou a enzimas que os metabolizam. No entanto, a maioria dos estudos apresenta limitações importantes.

As amostras utilizadas nestes estudos são pequenas, fazendo com que haja limitações importantes na interpretação dos resultados. O tamanho das amostras 
utilizadas em estudos de genética molecular têm sido um fator limitante, pois o poder de detecção de associação e ligação diminui proporcionalmente ao número de polimorfismos investigados.

Há um grande volume de estudos na literatura que testam associações entre genes candidatos e fenótipos comportamentais ou transtornos psiquiátricos, sendo que a grande maioria dos resultados não é replicada. Além dos problemas associados a múltiplas testagens, tamanho de amostra e estratificação populacional, é bastante provável que os polimorfismos associados a fenótipos complexos respondam isoladamente por uma pequena parcela da variância destes traços. O emprego da metodologia de haplótipos pode utilizar os resultados de estudos de associação para verificar se um conjunto de polimorfismos em um mesmo gene ou em genes em desequilíbrio de ligação pode estar associado a um determinado fenótipo, aumentando assim a variância atribuída aos fatores genéticos.

O desenho de estudo aqui utilizado apresenta algumas vantagens em relação aos estudos de caso-controle. A interferência provocada por estratificação populacional é grandemente atenuada através do pareamento com controles familiares, conforme discutido acima. 


\subsubsection{Associação Entre o Receptor de Serotonina subtipo 2A e Jogo Patológico:}

Este estudo encontrou uma associação positiva entre o alelo $\mathrm{C}$ do polimorfismo HTR2A T102C com o Jogo Patológico com um p=0.01 (Tabela 5), porém ao levar-se em conta a O.R. de 2.0 nota-se que, apesar de significante, o efeito deste polimorfismo é pequeno.

Prado-Lima et al. (2004) encontrou uma associação entre o polimorfismo HTR2A T102C e dependência a nicotina. Podemos sugerir que este polimorfismo contribua para a vulnerabilidade em outras dependencias, tanto comportamentais quanto a substancias.

Os achados de associação mais consistentes ligam o T102C 5HTR2A a manifestações de linha esquizofrênica. Em nosso estudo, a ocorrência de manifestações psicóticas de qualquer natureza implicaram na exclusão do estudo, assegurando a nãoocorrência de esquizofrenia em nossa amostra.

Além disso os receptores de serotonina do subgrupo 2 (5HT2) têm sido, como um todo, implicados como sendo centralmente contributivos ao sistema de gratificação (Kenna et al., 2004), e associados a uma maior vulnerabilidade a manifestações depressivas em condições desfavoráveis (Jokela et al.,2007), porém nenhum outro estudo investigou diretamente a associação entre o polimorfismo e Jogo Patológico, configurando-se o dado deste estudo num achado original. 
O presente estudo restringiu-se à realização de genotipagens possíveis a partir de reagentes disponíveis no Laboratório à época, não sendo possível realizar plenamente a Análise de Haplótipos. 


\section{CONCLUSÕES:}

- O presente achado de uma associação entre o polimorfismo HTR2A T102C e JP, embora consistente, apresenta uma O.R. de 2.0, mostrando um efeito pequeno deste polimorfismo no JP.

- O achado deste estudo pede o aprofundamento desses achados, e novos estudos mais detalhados (inclusive de haplótipos), para a melhor exploração do dado atual. 


\section{REFERÊNCIAS BIBLIOGRÁFICAS:}

Abdolmaleky, Hamid M. Genetics and Epigenetics in Major Psychiatric Disorders:

Dilemmas, Achievements, Applications, and Future Scope. American Journal of PharmacoGenomics. 5(3):149-160, 2005.

Alex KD, Yavanian GJ, Modulation of dopamine release by striatal 5-HT2C receptors. Synapse. 2005 Mar 15;55(4):242-51.

American Psychiatric Association (1994). Diagnostic and Statistical Manual of Mental Disorders, fourth edition. Washington, DC.

Arango $\mathbf{V}$ et al. Genetics of the serotonergic system in suicidal behavior. J Psychiatr Res. 2003 Sep-Oct; 37(5):375-86.

Beaudoin CM, Cox BJ. Characteristics of problem gambling in a Canadian context: a preliminary study using a DSM-IV-based questionnaire. Can J Psychiatry, 1999. 44(5):483-7.

Bhagwagar Z et al. Increased 5-HT2A Receptor Binding in Euthymic, Medication-Free Patients Recovered From Depression: A Positron Emission Study With [11C]MDL 100,907. American Journal of Psychiatry. 163(9):1580-1587, September 2006.

Bjork JM, Moeller FG, Dougherty DM, Swann AC, Machado MA, Hanis CL. 
Serotonin 2A receptor T102C polymorphism and impaired impulse control.

Black DW, Moyer T, Schlosser S. Quality of life and family history in pathological gambling. 2003 J Nerv Ment Dis191:124-6.

Black DW, Monahan PO, Temkit M, Shaw M A family study of pathological gambling. Psychiatry Res 141:295-303. 2006

Blaszczynski A, Steel Z, McConaghy N. Impulsivity in pathological gambling: the antisocial impulsivity. Addiction 1997 92(1):75-87.

Bonnaire C, Lejoyeux M, Dardennes R. Sensation seeking in a French population of pathological gamblers: comparison with regular and nongamblers. Psychol Rep. 2004 Jun;94(3 Pt 2):1361-71.

Bouwknecht JA, Hijzen TH, Van Der Gutten J, Maes RA, Hen R, Olivier B. Absence of 5-HT(1B) receptors is associated with impaired impulse control in male 5HT(1B) knockout mice. Biol Psychiatry. 2001 Apr 1;49(7):557-68.

Bradley SL, Dodelzon K, Sandhu HK, Philibert RA. Relationship of serotonin transporter gene polymorphisms and haplotypes to mRNA transcription. Am J Med Genet B Neuropsychiatr Genet. 2005 Jul 5;136(1):58-61. 
Castellani B, Wootton E, Rugle L, Wedgeworth R, Prabucki K, Olson R. Homelessness, negative affect, and coping among veterans with gambling problems who misused substances. Psychiatr serv. 1996; 47(3):398-9.

Cavedini P, Riboldi G., Keller R., D’Annucci G, Bellodi L. Frontal Lobe Dysfunction in Pathological Gambling Patients. Biol Psychiatry 2002;51:334-341.

Chambers RA, Taylor JR, Potenza MN. Developmental neurocircuitry of motivation in adolescence: a critical period of addiction vulnerability. Am J Psychiatry 2003; 160:1041-1052.

Chen K, Yang W, Grimsby J, Shih JC. The human 5-HT2 receptor is encoded by a multiple intron-exon gene. Brain Res. Molec. Brain Res. 14: 20-26, 1992

Cloninger CR, Van Eerdewegh P, Goate A, Edenberg HJ, Blangero J, Hesselbrock V, et al. Anxiety proneness linked to epistatic loci in genome scan of human personality traits. Am J Med Genet. 1998 Jul 10;81(4):313-7.

Coccaro EF, Kavoussi RJ, Richard JMD, Hauger RL, Cooper TB, Ferris, CF. Cerebrospinal Fluid Vasopressin Levels: Correlates with aggression and serotonin function in personality-disordered subjects. Arch Gen Psychiatry, Volume 55(8). August 1998.708-714. 
Comings DE, Gade R, Wu S, Chiu C, Dietz G, Muhleman D, et al. Studies of the potential role of the dopamine D1 receptor gene in addictive behaviors. Molecular Psychiatry (1997) 2, 44-56.

Comings DE, Gade-Andavolu R, Gonzalez N, Wu S, Muhleman D, Chen C, et al. The additive effect of neurotransmitter genes in pathological gambling. 2001. Clin Genet, 60, 107-16.

Comings DE, Gonzalez N, Wu S, et al. Studies of the 48 bp repeat polymorphism of the DRD4 gene in impulsive, compulsive, addictive behaviors: Tourette syndrome, ADHD, pathological gambling, and substance abuse. Am J Med Genet, 88, 358-68. 1999 Comings DE, Johnson JP, Gonzáles NS, Huss M, Saucier G, McGue M, et al. Association between the adrenergic alpha 2A receptor gene (ADRA2A) and measures of irritability, hostility, impulsivity, and memory in normal subjetcs. Psychiatr Genet. 2000 Mar; 10(1):39-42.

Comings DE, Rosenthal RJ, Lesieur HR, et al. A study of the dopamine D2 receptor gene in pathological gambling. Pharmoacogenetics (1996) 6, 223-34.

Conroy J, Meally E, Keraney G, Fitzgerald M, Gill M, Gallagher L. Serotonin transporter gene and autism: a haplotype analysis in an irish autistic population. Molecular Psychiatry (2004) 9, 587-593. 
Coutinho AM, Oliveira G, Morgadinho T, Fesel C, Macedo TR, Bento C, et al.

Variants of the serotonin transporter gene (SCL6A4) significantly contribute to hyperserotonemia in autism. Molecular Psychiatry (2004) 9, 264-271.

Da Silva Lobo DS, Vallada HP, Knight J, Martins SS, Tavares H, Gentil V, Kennedy JL Dopamine genes and pathological gambling in discordant sib-pairs. J Gambl Stud. 2007 Dec;23(4):421-33. 2007 Mar 30.

Dannon PN, Lowengrub K, Aizer A, Kotler M. Pathological gambling: comorbid psychiatric diagnoses in patients and their families. Isr $\mathbf{J}$ Psychiatry Relat Sci. 2006;43(2):88-92.

Darbyshire P, Oster C, Carrig H. Children of parent(s) who hve a gambling problem: a review of the literatureand commentary on research approaches. Health and Social Care in the Community (4), 185-1932001.

Dell'osso E, Sood E, Pallanti S, Baldini-Rossi N, Baker B. Comorbidity Issues in the Pharmacological Treatment of Pathological Gambling: A Critical Review. Clin Pract Epidemol Ment Health. 2005 Oct 10;1(1):21.

Dell'Osso B, Altamura AC, Allen A, Marazziti D, Hollander E. Epidemiologic and clinical updates on impulse control disorders - A critical review. Eur Arch Paychiatry Clin Neurosci (2006):464-475. 
Desai RA, Potenza MN. Gender differences in the associations between past-year gambling problems and psychiatric disorders. Soc Psychiatry Psychiatr Epidemiol. 2008 Mar;43(3):173-183. Epub 2007 Dec 15.

Duan J, Sanders AR, Molen JE, Martinolich L, Mowry BJ, Levinson DF, et al.

Polymorphisms in the 5'-untranslated region of the human serotonin receptor 1B 9HTR1B0 gene affect gene expression. Mol Psychiatry. 2003 Nov;8(11):901-10.

Dudbridge F. Pedigree disequilibrium tests for multilocus haplotypes. Genet Epidemiol 25:115-21, 2003.

Eisen SA, Slutske WS, Lyons MJ, Lassman J, Xian H, Toomey R, Chantarujikapong S, et al. The genetics of pathological gambling. Semin Clin Neuropsychiatry 2001. 6:195-204.

Evans J, Reeves B, Platt H, Leibenau A, Goldman D, Jefferson K, Nutt D. Impulsiveness, serotonin genes and repetition of deliberate self-harm (DSH). Psychol Med. 2000 Nov; 30(6):1327-34.

Evenden J (1999). Impulsivity: a discussion of clinical and experimental findings. Journal of Psychopharmacology 13(2) (1999) 180-192.

Fiorillo CD, Tobler PN, Schultz W. Discrete coding of reward probability and uncertainty by dopamine neurons. Science. 2003 Mar 21;299(5614):1898-902. 
Gambino G, Fitzgerald R, Shaffer H, Renner G, Courtnage P. Perceived family history of Problem gambling and scores on SOGS. Journal of Gamblng Studies vol 9(2), summer 1993 169-84.

Gerra G, Garofano L, Santoro G, Bosari S, Pellegrini C, Zaimovic A, Moi G, Bussandri M, Moi A, Brambilla F, Donnini C. (2004) Association between lowactivity serotonin transporter genotype and heroin dependence: behavioral and personality correlates.Am J Med Genet B Neuropsychiatr Genet 2004 Apr 1;126(1):3742.

Hamblin, MW; Metcalf, MA; McGuffin, RW; Karpells, S. Molecular cloning and functional characterization of a human 5-HT(1B) serotonin receptor: a homologue of the rat 5-HT(1B) receptor with 5-HT(1D)-like pharmacological specificity. Biochem. Biophys. Res. Commun. 184: 752-759, 1992.

Heils A, Teufel A, Petri S, Stoeber G, Riederer P, BengelD, et al. Allelic variation of human serotonin transporter gene expression. J Neurochem 1996; 66: 2621-2624.

Hill EM, Stoltenberg SF, Bullard KH, Li S, Zucker RA, Burmeister M. Antisocial alcoholism and serotonin-related polymorphisms: association tests. Psychiatric Genetics Volume 12:143-153 (2002). 
Hollander E, Sood E, Pallanti S, Baldini-Rossi N, Baker B. Pharmacological treatments of pathological gambling. J Gambl Stud. 2005 Spring;21(1):99-108.

Hranilovic D, Stefulj J, Furac I, Kubat M, Balija M, Jernej B. Serotonin transporter gene promoter (5-HTTLPR) and intron 2 (VNTR) polymorphisms in Croatian suicide victims. Biol Psychiatry. 2003 Nov 1;54(9):884-9.

Ibañez A, de Castro IP, Fernandez-Piqueras J, Blanco C, Saiz-Ruiz J. Pathological gambling and DNA polymorphic markers at MAO-A and MAO-B genes. Mol Psychiatry, 5, 105-9. 2000

Ibañez A, Blanco C, Donahue E, Lesieur HR, Perez de Castro I, FernandezPiqueras J, et al. Psychiatric comorbidity in pathological gamblers seeking treatment. Am J Psychiatry. 2001;158(10):1733-5.

Jernej B, Stefulj J, Hranilovic D, Balija M, Skavic J, Kubat M. Intronic polymorphism of tryptophan hydroxylase and serotonin transporter: indication for combined effect in predisposition to suicide. J Neural Transm. Jun;111(6):733-8. Epub $2004 \mathrm{Feb} 17$.

Jin H, Oksenberg D, Ashkenazi A, Peroutka SJ, Duncan AMV, Rozmahel R, et al. Characterization of the human 5hydroxytryptamine(1B) receptor. J. Biol. Chem. 267: 5735-5738, 1992. 
Jokela M, Lehtimaki T, Keltikangas-Jarvinen L. The influence of urban/rural residency on depressive symptoms is moderated by the serotonin receptor $2 \mathrm{~A}$ gene. Neuropsychiatric Genetics 144B:918-922. 2007

Kalechstein AD, Fong T, Rosenthal RJ, David A, Vanyo H, Newton T. Pathological gamblers demonstrate frontal lobe impairment consistent with that of methaphetaminedependent individuals. J Neuropsychiatry Clin Neurosci 19:3, Summer 2007.

Kalivas PW, Sorg BA, Hooks MS. The pharmacology and neural circuitry of sensitization to psychostimulants. Behav Pharmacol. 1993;4(4):315-334.

Kenna GA, McGeary JE, Swift, RM. Pharmacotherapy, pharmacogenomics, and the future of alcohol dependence treatment, part 2. Am J Health Syst Pharm, Volume 61(22). November 15, 2004.2380-97.

Kennedy JL, McMain S, Bulgin N, Sicard T, Bismil R, Ni X. Serotonin 2A receptor gene is associated with personality traits, but not to disorder, in patients with borderline personality disorder. Neurosci Lett. 2006 Nov 20;408(3):214-9. Epub 2006 Sep 26.

Kennedy JL, Lobo DSS. The Genetics of Gambling and Behavioral Addictions. CNS Spectr. 2006;11(12)931-939. 
Khait VD, Huang YY, Zalsman G, Oquendo MA, Brent DA, Harkavy-Friedman JM, et al. Association of serotonin 5HT2A receptor binding and the T102C polymorphism in depressed and healthy caucasian subjects. Neuropsychopharmacology (2005) 30, 166-172.

Knapp M, Seuchter SA, Baur MP. The haplotype-relative-risk (HRR) method for analysis of association in nuclear families. Am J Hum Genet. 1993 Jun;52(6):1085-93.

Kim SW \& Grant JE. Gender differences in pathological gamblers seeking medication treatment. Comprehensive Psychiatry 2002, 43 (1): 56-62.

Kim SW, Grant JE, Adson DE, Shin YC, Zaninelli R. A double-blind placebocontrolled study of the efficacy and safety of paroxetine in the treatment of pathological gambling. J Clin Psychiatry. 2002 Jun;63(6):501-7.

Koob GF Drug of abuse: anatomy, pharmacology and function of reward pathways. Trends Pharmacol. Sci 1992., 13:177-184.

Koob, GF, LeMoal M. Drug addiction, dysregulation of reward and allostasis. Neuropsychopharmacology. 2001 Feb; 24(2):97-129.

Koob, GF, LeMoal M. Addiction and the Brain Antireward System.Annu Rev Psychol. 2008 Jan 10;59:29-53. 
Kotler M, Dannon PN, Lowengrub K, Aizer A. Pathological Gambling: comorbid psychiatric diagnoses in patients and their families. Isr J Psychiatry Relat Sci. 2006;43(2):88-92.

Kruedelbach N, Walker HI, ChapmanHA, Haro G, Mateu C, Leal C. Comorbidity on disorders with loss of impulse-control: pathological gambling, addictions and personality disorders. Actas Esp Psiquiatr. 2006 Mar-Apr;34(2):76-82.

Ladouceur (1991). Prevalence estimates of pathological gambling in Quebec. Can J Psychiatry. 1991 Dec;36(10):732-4.

Lappalainen J, Dean M, Charbonneau L, Virkunnen M, Linnoila M, Goldman D (1995): Mapping of the serotonin 5HT1dB autoreceptor gene on chromosome 6 and direct analysis for sequence variants. Am J med Gen 1995; 60: 157-161.

Lappalainen J, Long JC, Eggert M, Ozaki N, Robin RW, Brown GL, et al. Linkage of antisocial alcoholism to the serotonin 5-HT1B receptor gene in 2 populations. Arch

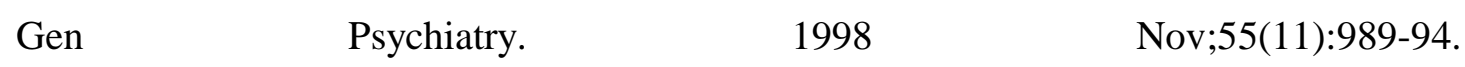
Lauzurica N, Hurtado A, Escarti A, Delgado M, Barrios V, Morande G, et al. Polymorphisms within the promoter and the intron 2 of the serotonin transporter gene in a population of bulimic patients. Neurosci Lett. 2003 Dec 11;352(3):226-30. 
Lee JH, Kim HT, Hyun DS. Possible association between serotonin transporter promoter region polymorphism and impulsivity in Koreans.Psychiatry Res. 2003 May $1 ; 118(1): 19-24$.

Lejoyeux M , Arbaretaz M, McLoughlin M, Ades J. Impulse control disorders and depression. Journal of Nervous and Mental Disorders 2002 May;190(5):310-4.

Lejoyeux M, McLoughlin M, Ades J. Epidemiology of behavioral dependence: literature review and results of original studies. Eur Psychiatry. 2000;15:129-134.

Lesch KP, Balling U, Gross J, Strauss K, Wolozin BL, Murphy DL. Organisation of the human serotonin transporter gene. J. Neural Trans. 95:157-162, 1994

Lesch KP, Bengel D, Heils A, Sabol SZ, Greenberg BD, Petri S, Benjamin J, Muller CR, Hammer DH, Murphy DL. Association of anxiety-related traits with a polymorphism in the serotonin transporter gene regulatory region. Science 1996; 274:1527-1531.

Lesch KP, Merschdorf U. Impulsivity, aggression, and serotonin: a molecular psychobiological perspective. Behav Sci Law. 2000;18(5):581-604.

Lesch KP, Merschdorf U. Impulsivity, aggression, and serotonin: a molecular psychobiological perspective. Behav Sci Law. 2000;18(5):581-604 
Lesch KP, Balling U, Gross J, Strauss K, Wolozin BL, Murphy DL. Organisation of the human serotonin transporter gene. J. Neural Trans. 95: 157-162, 1994.

Lesch, KP, Bengel D, Heils A, Sabol SZ, Greenberg BD, Petri S, et al. Association of anxiety-related traits with a polymorphism in the serotonin transporter gene regulatory region. Science 274: 1527-1530, 1996

Lesieur HR, Blume SB, Zoppa RM. Alcoholism, drug abuse, and gambling. Alcohol Clin Exp Res. 1986 Jan-Feb;10(1):33-8.

Li J, Wang Y, Zhou R, Zhang H, Yang L, Wang B, et al. Serotonin 5-HT1B receptor gene and attention deficit hyperactivity disorder in Chinese Han Subjects. Am J Genet B Neuropsychiatr Genet. 2005 Jan5;132(1):59-63.

Lobo DSS, Vallada Fo. HP, Gentil Fo.V. Características de personalidade e jogo patológico: análise comparativa de jogadores patológicos e seus irmãos. Tese apresentada à Faculdade de Medicina da Universidade de São Paulo, para obtenção de título de

Doutor em Ciências. Orientador: Prof. Dr. Valentim Gentil Filho; Co-orientador: Prof. Dr. Homero Pinto Vallada Filho.

Mann Arango V, Huang YY, Underwood MD, Mann JJ. Genetics of the serotonergic system in suicidal behavior. J Psychiatr Res. 2003 Sep-Oct;37(5):375-86. 
Martin ER, Monks SA, Warren LL, Kaplan NL. A test for linkage and association in general pedigrees: the pedigree disequilibrium test. Am J Hum Genet 2000; 67(1):14654.

Mason K, Arnold R. Problem gambling risk factors and associated behaviours and health status: results from the 2002/03 New Zealand Health Survey. N Z Med J. 2007 Jun 29;120(1257):U2604.

Masaki D, Tsuchida H, Kitabayashi Y, Tani N, Fukui K. Addictive behavior disorders Nihon Arukoru Yakubutsu Igakkai Zasshi. 2007 Oct;42(5):469-77

Minov C, Baghai TC, Schulle C, Zwanzger P, Schwarz MJ, Zill P, et al. Serotonin2A-receptor and -transporter polymorphisms: lack of association in patients with major depression. Neurosci lett. 2001 May 4;303(2):119-22.

Mochizuki D, Yuyama Y, Tsujita R, Komaki H, Sagai H. Cloning and expression of the human 5-HT1B-type receptor gene. Biochem. Biophys. Res. Commun. 185: 517-523, 1992.

Monterosso J, Ainslie G. Beyond discounting: possible experimental models of impulse control. Psychopharmacology Volume 146, Numer 4 October, 1999.Mundo E, Richter MA, Zai G, Sam F, McBride J, Macciardi F, et al. 5HT1dB receptor gene implicated 
in the pathogenesis of Obsessive-Compulsive Disorder: further evidence from a familybased association study. Mol Psychiatry. 2002;7(7):805-9.

Murphy GM Jr, Hollander SB; Rodrigues, HEBA, Kalechstein AD, Fong T, Rosenthal RJ, et al. Pathological gamblers demonstrate frontal lobe impairment consistent with that of metamphetamine-dependent individuals. J Neuropsychiatry Clin Neurosci 19:3, Summer 2007.

Murphy GM Jr, Hollander SB, Rodrigues HE, Kremer C, Schatzberg AF. Effects of the Serotonin Transporter Gene Promoter Polymorphism on Mirtazapine and Paroxetine Efficacy and Adverse Events in Geriatric Major Depression. Archives of General Psychiatry. 61(11):1163-1169, November 2004

Nacional Opinion Research Center of the University of Chicago, 1999 (NORC 1999). Gambling Impact and Behavior Study . Report to the National Gambling Impact Study Comisión, April, 1, 1999.

New AS, Gelernter J, Goodman M, Mitropoulou V, Koenigsberg H, Silvernamn J, et al. Suicide, impulsive aggression, and HTR1B genotype. Biol Psychiatry. $2001 \mathrm{Jul}$ $1 ; 50(1): 62-5$. 
Nielsen DA, Goldman D, Virkkunen M, Tokola R, Rawlings R, Linnoila M. Suicidality and 5-hydroxiindolacetic acid concentration associated with a tryptophan hydroxilase polymorphism. Arch Gen Psychiatry 1994 Jan; 51(1):34-8.

Nomura M, Nomura Y. Psychological, neurimaging, and biochemical studies on functional association between impulsive behavior and the 5-HT2A receptor gene polymorphism in humans. Ann N Y Acad Sci 2006 Nov; 1086:134-43.

Norra C, Mrazek M, Tuchtenhagen F, Gobbele R, Buchner H, Sass H, et al. Enhanced intensity dependence as a marker of low serotonergic neurotransmission in borderline personality disorder. J Psychiatr Res. 2003 Jan-Feb;37(1):23-33.

Oei, TPS, Raylu N. Familial influence on offspring gambling: a cognitive mechanism for transmission of gambling behavior in families. Psychological Medicine, 2004, 34, 1279-1288.

Olds J, Milner P (1954). Positive reinforcement products by electrical stimulation of septal area and other regions of the rat brain. J. Comp. Physiol. Psychol., 47: 419-27

Oswald P, Souery D, Massat I, Del-Favero J, Linotte Sylvie, Papadimitriou G, et al. Lack of association between the 5HT2A receptor polymorphism (T102C) and unipolar affective disorder in a multicentric European study.European Neuropsychopharmacology 13 (2003) 365-368. 
Ozaki N, Rosenthal NE, Pesonen U, Lappalainen J, Feldman-Naim S, Schwartz PJ, et al. Two Naturally Ocurring Amino Acid Substitutions of the 5HT2A Receptor: Similar Prevalence in Patients With Seasonal Affective Disorder and Controls. Biol Psychiatry 1996;40:1267-1272.

Pallanti S, Baldini RN, Sood E, Hollander E. Nefazodone treatment of pathological gamgling: a prospective open-labelcontrolled trial. Pallanti S, Baldini RN, Sood E, Hollander E. J Clin Psychiatry. 2002 Nov; 63(11):1034-9.

Parsian A. Sequence analysis of exon 8 of MAO-A gene in alcoholics with antisocial personality and notmal controls. Genomics. 1999 Feb 1;55(3):290-5.

Perez de Castro I, Ibañez A, Saiz-Ruiz J, Fernandez-Piqueras J. Genetic contribution to pathological gambling: possible association between a functional DNA polmorphism at the serotonin transporter gene (5HTT) and affected men. 1999 Pharmacogenetics, 9, 397-400.

Perez de Castro I, Ibañez A, Saiz-Ruiz J, Fernandez-Piqueras J. Concurrent positive association between pathological gambling and functional DNA polymorphisms at the MAO-a and the 5-HT transporter genes. 2002. Mol Psychiatry, 7, 927-8. 
Perez de Castro I, Santos J, Torres P, Visedo G, Saiz-Ruiz J, Llinares C, Fernández-Piqueras J. A weak association between TH and DRD2 genes and bipolar affective disorder in a Spanish sample. J Med Genet. 1995 Feb;32(2):131-4.

Perez de Castro I, Ibañez A, Torres P, Saiz-Ruiz J, Fernandez-Piqueras J. Genetic association study between pathological gambling and a functional DNA polymorphism at the D4 receptor gene, Pharmacogenetics (1997) 7, 345-8.

Petry NM. Psychiatric symptoms in problem gambling and non-problem gambling substance abusers. Am J Addict. 2000; 9:163-71.

Petry NM, Stinson FS, Grant BF. Comorbidity of DSM-IV Pathological gambling and Other Psychiatric Disorders: Results From the National Epidemiologic Survey on Alcohol and Related Conditions. J Clin Psychiatry 66:5, May 2005.

Pietrzak RH, Morasco BJ, Blanco C, Grant BF, Petry NM. Gambling level and psychiatric and medical disorders in older adults: results from the National Epidemiologic

Survey on Alcohol and Related Conditions. Am J Geriatr Psychiatry. 2007 Apr;15(4):301-13. 
Phillipe F, Vallerand RJ (2007) Prevalence Rates of Gambling Problems in Montreal, Canada: A Look at Old adults and the roll of passion. J Gambl Stud, 2007 Mar 13, Epub ahead of publishing.

Pogue-Geile M, Ferrell R, Deka R, Debski T, Manuch S. Personality traits and dopamine D4 receptor polymorphisms: a twin and genetic association Human noveltyseeking study. Am J Med Genet. 1998 Feb 7;81(1)44-8.

Potenza MN, Fiellin DA, Heninger GR, Rounsaville BJ, Mazure CM. Gambling: an addictive behavior with health and primary care implications. J Gen Intern Med. 2002;17(9):721-32.

Potenza MN, Leung HC, Blumberg HP et al. An FMRI Stroop task study of ventromedial prefrontal cortical function in pathological gamblers. Am J Psychiatry. 2003a;160(11):1990-4.

Potenza MN, Xian H, Shah K, Scherrer JF, Eisen SA. Shared genetic contributions to pathological gambling and major depression in men. Arch Gen Psychiatry. 2005;62:1015-1021.

Prado-Lima PAS, Chatkin JM, Taufer M, Oliveira G, Silveira E, Neto CA, et al. Polymorphism of 5HT2A serotonin receptor gene is implicated in smoking addiction. Neuropsychiatric Genetics 128B 90-93 (2004). 
Preuss UW, Koller G, Bondy B, Bahlmann M, Soyka M. Impulsive traits and 5HT2A receptor promoter polymorphism in alcohol dependents: possible association but no influence of personality disorders. Neuropsychobiology. 2001;43(3):186-91.

Puig, MV, Artigas F, Celada P. Modulation of the Activity of Pyramidal Neurons in Rat Prefrontal Cortex by Raphe Stimulation In Vivo: Involvement of Serotonin and GABA. Cerebral Cortex. 15(1):1-14, January 2005.

Rammamorthy S; Bauam AL, Moore KR, Han H, Yang-Feng T, Chang AS, et al. Antidepressant-and cocaine-sensitive human serotonin transporter: molecular cloning expression, and chromosomal localization. Proc. Nat. Acad. Sci. 90:2542-2546, 1993.

Riboldi G, Keller R, D’Annucci A, Bellodi L. Frontal lobe disfunction in pathological gambling patients. Biol Psychiatry. 2002 Feb 15;51(4):334-41.

Rubia K, Lee F, Cleare AJ, Tunstall N, Fu CH, Brammer M, et al. Tryptophan depletion reduces right inferior pré-frontal activation during response inhibition in fast, event-related fMRI. Psychopharmacology (Berl). 2005 Jan 26

Runeson, Bo; Åsberg, Marie M.D. Family History of Suicide Among Suicide Victims.Volume 160(8), August 2003, p 1525-1526

Sakado K, Sakado M, Muratake T, Mundt C, Someya T. A psychometrically derived impulsive trait related to a polymorphism in the serotonin transporter gene-linked 
polymorphic region (5-HTTLPR) in a Japanese nonclinical population: assessment by the Barratt impulsiveness scale (BIS). Am J Med Genet B Neuropsychiatr Genet. 2003.

Scherrer FJ, Xian H, Kapp JMK, Waterman B, Shah KR, Volberg R, et al. Association between exposure to childhood and lifetime traumatic events and lifetime pathological gambling in a twin cohort. The Journal of Nervous and mental Disease. Volume 195, Number 1, January 2007.

da Silva Lobo DS, Vallada HP, Knight J, Martins SS, Tavares H, Gentil V, Kennedy JL. Dopamine genes and pathological gambling in discordant sib-pairs. J Gambl Stud. 2007 Dec;23(4):421-33.

Scherrer JF, Slutske WS, Xian H, Waterman B, Shah KR, Volberg R, et al. Factors associated with pathological gambling at 10-year follow-up in a national sample of middle-aged men. Addiction. 2007 Jun;102(6):970-8.

Schofield G, Mummery K, Wang W, Dickson G. Epidemiological study of gambling in the non-metropolitan region of central Queensland. Aug J Rural Health. 2004;12(1):610.

Seth AE, Lin N, Lyons MJ, Scherrer JF, Griffith K, True WR, et al. Familial influences on gambling behavior : an analysis of 3359 twin pairs. Addiction (1998) 93(9), 1375-1384. 
Shaffer HJ, Hall MN, Vander-Bilt J. Estimating the prevalence of disordered gambling behavior in the United States and Canada: a research synthesis. Am J Public health. 1999;89(9):1369-76.

Shaffer HJ, Korn DA. Gambling and related mental disorders: a public health analysis. Annu Rev Public Health 23:171-212.2002.

Shaffer H, Hall M, Van der Bilt J. Estimating the prevalence of disordered gambling behavior in the United States and Canada. A meta-analysis. Presidents and Fellows of Harvard College, Boston. 1997.

Schaffer HJ, Hall MN. Updating and refining prevalence estimates of disordered gambling behaviour in the United States and Canada. Can J Public Health 92:168-72. 2001.

Shaffer HJ, Korn DA. Gambling and related mental disorders: a public health analysis. Annu Rev Public Health, 2002:23:171-212

Shankman SA, Klein DN, Lewinsohn PM, Seeley JR, Small JW. Family study of subthreshold psychopathology in a community sample. Psychol Med. 2007 Oct 15;:1-12 
Sheehan K, Lowe N, Kirley A, Mullins C, Fitzgerald M, Gill M, et al. Tryptophan hydroxylase 2 (TPH2) gene variants associated with ADHD. Mol Psychiatry. 2005 Jun 7; [Epub ahead of print].

Sinha R, Cloninger CR, Parsian A. Linkage disequilibrium and haplotype analysis between serotonin receptor 1B gene variations and subtypes of alcoholism. Am J Med Genet B Neuropsychiatr Genet. 2003 Aug 15;121(1):83-8.

Slutske WS, Eisen S, True WR, Lyons MJ, Goldberg J, Tsuang M (2000): Common genetic vulnerability for pathological gambling and alcohol dependence in men. Arch Gen Psychiatry 57:666-73.

Slutske WS, Eisen S, Xian H, et al. A twin study of the association between pathological gambling and antisocial personality disorder. J Abnorm Psychol 110:297308. 2001

Stanley B, Molcho A, Stanley M, Winchel R, Gameroff MJ, Parsons B, et al. Association of aggressive behavior with altered serotonergic function in patients who are not suicidal. Am J Psychiatry. 2000 Apr;157(4):609-14.

Stefulj J, Buttner A, Skavic J, Zill P, Balija M, Eisenmenger W, et al. Serotonin 1B (5HT1-B) receptor polymorphism (G861C) in suicide victims: association 
studies in German and Slavic population. Med Genet B Neuropsychiatr Genet. 2004 May $15 ; 127(1): 48-50$.

Steiger H, Gauvin L, Israel M, Kin NM, Young SN, Roussin J. Serotonin function, personality-trait variations, and childhood abuse in women with bulimia-spectrum eating disorders. J Clin Psychiatry. 2004 Jun;65(6):830-7.

Stuhldreher WL, Stuhldreher TJ, Forrest KY. Gambling as an emerging health problem on campus. J am Coll Health. 2007 Jul-Aug;56(1):75-83.

Stewart SH, Kushner MG. Recent research on the comorbidity of alcoholism and pathological gambling. Alcohol Clin Exp Res. 2003; 27(2):285-91.

Tavares H (2000). Jogo patológico e suas correlações com o espectro impulsivocompulsivo. Tese defendida para obtenção do grau de Doutor em Medicina - área de interesse em Psiquiatria, defendida na Faculdade de Medicina da Universidade de São Paulo-SP, Brasil.

Toneatto T, Millar G. Assessing and treating problem gambling: empirical status and promising trends. Can J Psychiatry. 2004 Aug;49(8):517-25.

Tot S, Erdal M.E., Yazici K., Yazici A. E., Metin O. T102 and -1438 G/A polymorphisms of the 5-ht2a receptor gene in Turkish patients with obsessivecompulsive disorder. European Psychiatry 18 (2003) 249-254. 
Visser HM, Van der Mast RC. Bipolar disorder, antidepressants and induction of hypomania or mania. A systematic review. World J Biol Psychiatry. 2005;6(4):231-41.

Walderhaug E, Lunde H, Nordvik JE, Landro NI, Refsum H, Magnusson A. Lowering of serotonin by rapid tryptophan depletion increases impulsiveness in normal individuals. Psychopharmacology (Berl). 2002 Dec;164(4):385-91. Epub 2002 Oct 12

Weese-Mayer DE, Zhou L, Berry-Kravis EM, Maher BS, Silvestri JM, Marazita ML. Association of the Serotonin Transporter Gene With Sudden Infant Death Syndrome: A Haploype Analysis. American Journal of Medical Genetics 122A:238-245 (2003).

Williams J, McGuffin P, Nothen M, Owen MJ, EMASS Collaborative Group. Meta-analysis of associoation between the 5-HT (2A) receptor T102C polymorphism of the 5-hydroxytryptophan type 2a-receptor gene. European Multicentre Association Study of Schizophrenia (EMASS) Group. Lancet 347:1294-1296, 1996.

Williams J, Spurlock G, McGuffin P, Mallet J, Nothen MM, Gill M, et al. Association between schizophrenia and T102C polymorphism of the 5hydroxytryptophan type 2a-receptor gene. European Multicentre Association Study of Schizophrenia (EMASS) Group. Lancet 347:1294-1296, 1996. 
Winters KC, Rich T. A Twin study of adult gambling behavior. Journal of Gambling Studies 14:213-225. 1999

Wise RA Rompre, PP. Brain dopamine and reward. Annu Rev. Psychol., 40:191-225.

Zalsman G, Huang YY, Oquendo M, Burke AK, Hu XZ, Brent DA, Ellis SP,

Goldman D, Mann, JJ. Association of a triallelic serotonin transporter gene promoter region (5-HTTLPR) polymorphism with stressful life events and severity of depression. Am J Psychiatry, Volume 163(9).September 2006.1588-1593.

Zuckerman M. Behavioral expressions and biosocial bases of sensation seeking. Cambridge University Press, New York. 1994. Capitulo 9. Págs. 225-258. 